\title{
Interplay between Facilitation, Depression, and Residual Calcium at Three Presynaptic Terminals
}

\author{
Jeremy S. Dittman, Anatol C. Kreitzer, and Wade G. Regehr \\ Department of Neurobiology, Harvard Medical School, Boston, Massachusetts 02115
}

Synapses display remarkable alterations in strength during repetitive use. Different types of synapses exhibit distinctive synaptic plasticity, but the factors giving rise to such diversity are not fully understood. To provide the experimental basis for a general model of short-term plasticity, we studied three synapses in rat brain slices at $34^{\circ} \mathrm{C}$ : the climbing fiber to Purkinje cell synapse, the parallel fiber to Purkinje cell synapse, and the Schaffer collateral to CA1 pyramidal cell synapse. These synapses exhibited a broad range of responses to regular and Poisson stimulus trains. Depression dominated at the climbing fiber synapse, facilitation was prominent at the parallel fiber synapse, and both depression and facilitation were apparent in the Schaffer collateral synapse. These synapses were modeled by incorporating mechanisms of short-term plasticity that are known to be driven by residual presynaptic calcium $\left(\mathrm{Ca}_{\text {res }}\right)$. In our model, release is the product of two factors: facilitation and refractory depression. Facilitation is caused by a calciumdependent increase in the probability of release. Refractory depression is a consequence of release sites becoming transiently ineffective after release. These sites recover with a time course that is accelerated by elevations of $\mathrm{Ca}_{\text {res. }}$. Facilitation and refractory depression are coupled by their common dependence on $\mathrm{Ca}_{\text {res }}$ and because increased transmitter release leads to greater synaptic depression. This model captures the behavior of three different synapses for various stimulus conditions. The interplay of facilitation and depression dictates synaptic strength and variability during repetitive activation. The resulting synaptic plasticity transforms the timing of presynaptic spikes into varying postsynaptic response amplitudes.

Key words: short-term plasticity; residual calcium; cerebellar granule cell; cerebellar Purkinje cell; climbing fiber; Schaffer collateral; hippocampal CA1 pyramidal cell; synaptic model
Fast, chemical synaptic transmission provides the dominant means of information transfer between neurons, but presynaptic action potentials do not all give rise to identical postsynaptic responses. It has long been known that the history of recent activity dynamically regulates the strength of most synapses (Eccles et al., 1941; Feng, 1941; Magleby, 1987; Zucker, 1989). By converting trains of action potentials into varying amplitudes of postsynaptic responses, synapses perform a type of temporal filtering (Lisman, 1997; Zador and Dobrunz, 1997). This synaptic plasticity results from presynaptic changes in neurotransmitter release (Varela et al., 1997) and alterations in the responses of postsynaptic neurons to a given amount of transmitter (Trussell and Fischbach, 1989; Magee et al., 1998). In this study, we focus on how the temporal pattern of activity influences neurotransmitter release on the time scale of milliseconds to seconds.

Synapses show a wide range of responses to high-frequency stimulation such as enhancement, depression, and more complex behaviors (Feng, 1941; Eccles et al., 1964; von Gersdorff et al., 1997; Selig et al., 1999; Kreitzer and Regehr, 2000). This diversity has important implications for the transmission of information in the CNS. To demonstrate the effects of use-dependent plasticity on synaptic transmission, we considered some possible responses to a typical spike train recorded in vivo (Fig. $1 A$ ). We simulated responses to this spike train for two synapses with different

\footnotetext{
Received Oct. 8, 1999; revised Nov. 16, 1999; accepted Dec. 6, 1999.

This work was supported by National Institutes of Health Grant R01-NS32405-01. We thank John Assad, Adam Carter, Chinfei Chen, and Matthew Xu-Friedman for comments on this manuscript.

Correspondence should be addressed to Dr. Wade Regehr, Department of Neurobiology, Harvard Medical School, 220 Longwood Avenue, Boston, MA 02115. E-mail: wade_regehr@hms.harvard.edu.

Copyright (c) 2000 Society for Neuroscience $\quad 0270-6474 / 00 / 201374-12 \$ 15.00 / 0$
}

presynaptic properties but identical postsynaptic properties (Fig. $1 B, C)$. The temporal pattern of postsynaptic depolarization in each example reflected the amount of facilitation and depression present during periods of high- and low-frequency activity. At one synapse, bursts of activity transiently boosted synaptic strength (Fig. 1B). In contrast, the other synapse conveyed the average rate of activity through EPSPs of relatively constant amplitude (Fig. 1C). These simulations highlight the importance of understanding presynaptic properties that determine the influence of a neuron on the firing of its targets.

To understand the mechanisms underlying presynaptic plasticity, it is necessary to consider presynaptic residual calcium $\left(\mathrm{Ca}_{\text {res }}\right)$ (Zucker, 1999). In contrast to the high calcium levels that trigger transmitter release after presynaptic depolarization $(>10$ $\mu \mathrm{M}$ for $\sim 1 \mathrm{msec}), \mathrm{Ca}_{\text {res }}$ is the modest elevation in calcium levels (hundreds of nanomolar) lasting for hundreds of milliseconds. During periods of high-frequency presynaptic activity, $\mathrm{Ca}_{\text {res }}$ accumulates and is involved in various short-term plasticities such as facilitation (Katz and Miledi, 1968; Zucker and Stockbridge, 1983; Kamiya and Zucker, 1994; Atluri and Regehr, 1996), augmentation (Zengel et al., 1980; Swandulla et al., 1991; Delaney and Tank, 1994), post-tetanic potentiation (Delaney et al., 1989), and recovery from presynaptic depression (Dittman and Regehr, 1998; Stevens and Wesseling, 1998; Wang and Kaczmarek, 1998). It is likely that differences in the contribution of various calciumdependent mechanisms to synaptic strength will add to the diversity of synaptic behavior during repetitive activation.

Here, we present a simple framework for understanding synaptic dynamics in terms of underlying plasticities and $\mathrm{Ca}_{\text {res }}$. We build on different aspects of models that were developed previously (Magleby, 1987; Abbott et al., 1997; Markram et al., 1998) 

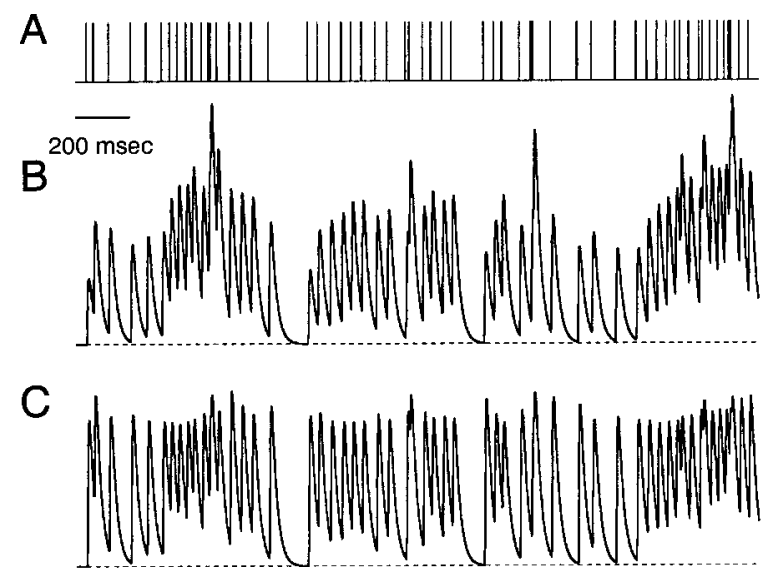

Figure 1. Effects of presynaptic plasticity on synaptic transmission. A, Representative spike train recorded from the basal ganglia of an awake, behaving macaque. $B, C$, Simulated EPSPs resulting from the stimulus in $A$ (see Materials and Methods). The mean peak EPSPs were the same in both examples (i.e., synaptic currents were normalized to give the same average depolarization). The only difference between the presynaptic terminals in $B$ and $C$ is the amount of facilitation and initial release probability $\left(F_{1}\right)$. Comparison of the traces reveals the different temporal patterns of depolarization associated with each type of presynaptic plasticity. The postsynaptic cell was simulated using a passive single compartment model with parameters $\tau_{\mathrm{m}}=20 \mathrm{msec}, V_{\text {rest }}=-70 \mathrm{mV}, R_{\mathrm{N}}=100$ $\mathrm{M} \Omega$. The FD model parameters for $B$ were $\rho=3.1, F_{1}=0.05, \tau_{\mathrm{F}}=100$ msec, $\tau_{\mathrm{D}}=50 \mathrm{msec}, k_{\max }=30 \mathrm{sec}^{-1}, k_{\mathrm{o}}=2 \mathrm{sec}^{-1}, K_{\mathrm{D}}=2$. Model parameters for $C$ were $\rho=2.2, F_{1}=0.24, \tau_{\mathrm{F}}=100 \mathrm{msec}, \tau_{\mathrm{D}}=50 \mathrm{msec}$, $k_{\text {max }}=30 \mathrm{sec}^{-1}, k_{\mathrm{o}}=2 \mathrm{sec}^{-1}, K_{\mathrm{D}}=2$. The spike train in $A$ was kindly provided by John Assad and Irwin Lee.

and take advantage of recent clarification of the role of $\mathrm{Ca}_{\text {res }}$ in facilitation and recovery from depression. We develop an analytical expression for the use-dependent enhancement and depression of transmitter release driven by $\mathrm{Ca}_{\text {res }}$ and apply the scheme to three synapses with very different properties. This highly simplified model of presynaptic plasticity captures much of the apparent complexity observed during realistic Poisson train stimuli at all three synapses.

\section{MATERIALS AND METHODS}

Synaptic physiology. For cerebellar recordings, 300- $\mu$ m-thick transverse slices were cut from the cerebellar vermis of 9- to 14-d-old Sprague Dawley rats (Llano et al., 1991). For hippocampal recordings, 300- $\mu \mathrm{m}-$ thick slices were cut from the hippocampus of 16- to 19-d-old Sprague Dawley rats, and the CA3 region was removed. Cerebellar slices were superfused with an external solution containing (in $\mathrm{mm}$ ): $125 \mathrm{NaCl}, 2.5$ $\mathrm{KCl}, 1.5 \mathrm{CaCl}_{2}, 1 \mathrm{MgCl}_{2}, 26 \mathrm{NaHCO}_{3}, 1.25 \mathrm{NaH}_{2} \mathrm{PO}_{4}$, and 25 glucose, bubbled with $95 \% \mathrm{O}_{2} / 5 \% \mathrm{CO}_{2}$. For hippocampal slices, the external divalents were $2 \mathrm{CaCl}_{2}$ and $3 \mathrm{MgCl}_{2}$ to minimize multisynaptic activity and $\mathrm{CA} 1$ population spikes during repetitive stimulation. Flow rates were $4-6 \mathrm{ml} / \mathrm{min}$ at $34^{\circ} \mathrm{C}$. Bicuculline $(20 \mu \mathrm{M})$ was added to the external solution to suppress synaptic currents mediated by $\mathrm{GABA}_{\mathrm{A}}$ receptors. During parallel fiber trains, the $\mathrm{GABA}_{\mathrm{B}}$ receptor antagonist CGP55845a $(2 \mu \mathrm{M})$, the adenosine $\mathrm{A}_{1}$ receptor antagonist DPCPX $(5 \mu \mathrm{M})$, and the mGluRIII antagonist CPPG $(30 \mu \mathrm{M})$ were included in the external saline. During studies of the hippocampal Schaffer collateral synapse, (R)-CPP $(5 \mu \mathrm{M})$ was present to suppress NMDA receptor-mediated currents.

Whole-cell recordings of Purkinje cells and CA1 pyramidal cells were obtained as described previously (Mintz et al. 1995) with an internal solution of (in mM): $35 \mathrm{CsF}, 100 \mathrm{CsCl}, 10$ EGTA, $10 \mathrm{HEPES}$, and 0.2 D600, adjusted to $\mathrm{pH} 7.2$ with $\mathrm{CsOH}$. Synaptic currents were monitored at a holding potential of $-40 \mathrm{mV}$ to inactivate voltage-gated $\mathrm{Na}$ channels, and D600 was included to block voltage-gated calcium channels. In some CA1 recordings, QX-314 (5 mM) was also included in the internal solution. The access resistance and leak current $(-20$ to $-200 \mathrm{pA}$ holding at $-40 \mathrm{mV}$ ) were monitored continuously. Experiments were rejected if either access resistance or leak current increased significantly during recording. Presynaptic fibers were stimulated with two glass electrodes (tip diameter, 10-12 $\mu \mathrm{m}$ ) filled with external saline solution placed in the molecular layer. Brief pulses $(200 \mu \mathrm{sec})$ of current $(5-15$ $\mu \mathrm{A})$ were passed between the two stimulating electrodes. This configuration greatly reduced the size of the stimulus artifact. The inter-stimulus interval was $2 \mathrm{~min}$ for trains of $\leq 10$ stimuli and $3 \mathrm{~min}$ for trains of $>10$ stimuli. Low stimulus intensities were used to keep initial synaptic currents small ( -50 to $-150 \mathrm{pA}$ ) thereby minimizing series resistance errors during the train.

Detecting presynaptic calcium transients. Parallel fibers, made up of granule cell axons and presynaptic terminals, were labeled with a highpressure stream of the low-affinity calcium indicator magnesium green-AM (Molecular Probes, Eugene, OR) (Zhao et al., 1996) using techniques developed previously (Regehr and Atluri, 1995). Parallel fiber tracts were stimulated extracellularly, and epifluorescence was measured with a photodiode from a spot several hundred micrometers from the loading site, where the vast majority of the fluorescence signal arises from parallel fiber presynaptic boutons that synapse onto Purkinje cells. The peak $\Delta F / F$ change produced by a single stimulus was used as a linear measure of presynaptic calcium influx, as established previously (Regehr and Atluri, 1995).

Data acquisition and analysis. Outputs of the Axopatch 200A were filtered at $1 \mathrm{kHz}$ and digitized at $20 \mathrm{kHz}$ with a 16-bit $\mathrm{D} / \mathrm{A}$ converter (Instrutech, Great Neck, NY) using Pulse Control software (Herrington and Bookman, 1995). Random train stimuli were generated off-line and sent through the DAC to the stimulus isolation unit. Both on- and off-line analysis as well as computer simulations were performed using Igor Pro software (Wavemetrics, Lake Oswego, OR).

Model of use-dependent plasticity driven by presynaptic calcium. We modeled the experimentally determined EPSC size as the product of the number of physical release sites $\left(N_{\mathrm{T}}\right)$ and the fraction of sites that undergo release on arrival of an action potential. This fraction was divided into two parts: a facilitation component $(F)$ and a depression component $(D)$, both of which could range between 0 and 1 :

$$
E P S C=\alpha \cdot N_{\mathrm{T}} \cdot F \cdot D .
$$

Note that release is scaled by the average mEPSC amplitude $(\alpha)$ to produce the final EPSC amplitude. The depression variable was set to unity at rest, reflecting the assumption that all potential release sites are available for release when no release activity has occurred for some time. Therefore, the resting probability of release is equivalent to the initial value of $F\left(F_{1}\right)$.

\section{Facilitation}

Enhancement of release was assumed to be directly related to the equilibrium occupancy of the release site by a calcium-bound molecule CaX $X_{\mathrm{F}}$ with dissociation constant, $K_{\mathrm{F}}$ (see Fig. $3 A$ for reaction scheme):

$$
F(t)=\frac{1}{1+K_{\mathrm{F}} / \operatorname{CaX} X_{\mathrm{F}}(t)},
$$

where $C a X_{\mathrm{F}}$ decays exponentially with time constant $\tau_{\mathrm{F}}$ after a jump of size $\Delta_{\mathrm{F}}$ after an action potential at time $t_{\mathrm{o}}$ :

$$
\frac{d C a X_{\mathrm{F}}}{d t}=-C a X_{\mathrm{F}}(t) / \tau_{\mathrm{F}}+\Delta_{\mathrm{F}} \cdot \delta\left(t-t_{\mathrm{o}}\right)
$$

where $\delta(t)$ is the Dirac delta function and is defined to have units of $\mathrm{sec}^{-1}$. Note that the notation here differs from a previous publication in which we defined $\delta(t)$ to be unitless (Dittman and Regehr, 1998). The treatment of $C a X_{\mathrm{F}}$ does not take into account the underlying decay time course of free calcium, but instead serves as an approximate description based on experimental evidence that the decay of paired-pulse facilitation is roughly exponential in nature (Atluri and Regehr, 1996). $\tau_{\mathrm{F}}$ represents the decay time constant, which was measured to be $\sim 100 \mathrm{msec}$ at the granule cell to Purkinje cell synapse at $34^{\circ} \mathrm{C}$ (Atluri and Regehr, 1996). We explored variations of Equation 2 with a power law relationship between facilitation and $\mathrm{CaX}$, but the performance of the model was not improved with these modifications. We therefore chose the linear relationship for the sake of simplicity. To create an analytical expression for Equations 2 and 3 where $C a X_{\mathrm{F}}$ is allowed to decay to 0 , Equation 2 
was modified with the addition of a baseline release probability $F_{1}$ in the absence of $C a X_{\mathrm{F}}$ :

$$
F(t)=F_{1}+\frac{1-F_{1}}{1+K_{\mathrm{F}} / C a X_{\mathrm{F}}(t)} .
$$

With this change, $F(t)$ ranges from $F_{1}$ to 1 as $C a X_{\mathrm{F}}$ increases from 0 . Given a quiescent presynaptic terminal with $C a X_{\mathrm{F}}=0$ and $F=F_{1}$, then immediately after stimulation with a single action potential, $\mathrm{Ca} X_{\mathrm{F}}$ increases to $\Delta_{\mathrm{F}}$ and $F$ increases to:

$$
F_{2}=F_{1}+\frac{1-F_{1}}{1+K_{\mathrm{F}} / \Delta_{\mathrm{F}}}
$$

$N_{\mathrm{T}} D_{1} F_{1}$ sites have undergone release and entered a refractory state while $N_{\mathrm{T}}\left(1-D_{1} F_{1}\right)$ sites remain available. If a second stimulus occurs just after the first stimulus such that no recovery from the refractory state has occurred, then the second EPSC will be determined by the increased release probability $F_{2}$ and the remaining number of release sites as follows:

$$
\operatorname{EPSC}_{2}=\alpha \cdot N_{\mathrm{T}} \cdot\left(1-D_{1} \cdot F_{1}\right) \cdot F_{2} .
$$

Therefore, the facilitation ratio $(\rho)$ can be expressed as:

$$
\rho=\frac{E P S C_{2}}{E P S C_{1}}=\frac{\alpha \cdot N_{\mathrm{T}} \cdot\left(1-D_{1} \cdot F_{1}\right) \cdot F_{2}}{\alpha \cdot N_{\mathrm{T}} \cdot D_{1} \cdot F_{1}}=\frac{\left(1-F_{1}\right) \cdot F_{2}}{F_{1}},
$$

if $D_{1}=1$ (i.e., all release sites are initially available). Because $F_{2}$ cannot exceed unity, one can establish an upper bound on the initial probability of release: $F_{1} \leq 1 /(1+\rho)$. By substituting Equation 4 into 6 for $F_{2}$ and solving for the constant $K_{\mathrm{F}} / \Delta_{\mathrm{F}}$, one arrives at:

$$
K_{\mathrm{F}} / \Delta_{\mathrm{F}}=\frac{1-F_{1}}{\left(F_{1} /\left(1-F_{1}\right)\right) \cdot \rho-F_{1}}-1,
$$

so the value of $K_{\mathrm{F}} / \Delta_{\mathrm{F}}$ is entirely determined by the experimentally observed value of facilitation and the initial release probability.

During regular stimulus trains at rate $r$, the amplitude of $C a X_{\mathrm{F}}$ just before the $i$ th stimulus is given by:

$$
\operatorname{CaX}_{\mathrm{F}_{\mathrm{i}}}(r)=\operatorname{CaX}_{\mathrm{F}_{x}}(r) \cdot\left[1-\exp \left(-(i-1) / r \tau_{\mathrm{F}}\right)\right]
$$

where:

$$
\operatorname{CaX} X_{\mathrm{F}_{\infty}}(r)=\Delta_{\mathrm{F}} \cdot\left[\exp \left(1 / r \tau_{\mathrm{F}}\right)-1\right]^{-1} .
$$

The value of release probability just before the $i$ th stimulus can be expressed as:

$$
F_{\mathrm{i}}(r)=F_{1}+\frac{1-F_{1}}{1+K_{\mathrm{F}} / C a X_{\mathrm{F}_{\mathrm{i}}}(r)},
$$

using Equation 2a. Release probability approaches a steady-state value of:

$$
F_{\infty}(r)=F_{1}+\frac{1-F_{1}}{1+K_{\mathrm{F}} / \operatorname{CaX} X_{\mathrm{F}_{\infty}}(r)} .
$$

\section{Calcium dependence and kinetics of recovery from depression}

Our model of recovery from depression has been previously described for the climbing fiber [see Scheme II in Dittman and Regehr (1998)]. Here, we have adopted different symbols for some of the parameters for clarity. We use $C a X_{\mathrm{D}}$ in place of $C a$ to refer to the calcium-bound site

\begin{tabular}{|c|c|}
\hline Symbol & Definition \\
\hline $\operatorname{CaX} \mathrm{F}_{\mathrm{F}}$ & Concentration of calcium-bound site $X_{\mathrm{F}}$ \\
\hline $\operatorname{CaX}_{\mathrm{D}}$ & Concentration of calcium-bound site $X_{\mathrm{D}}$ \\
\hline$F$ & $\begin{array}{l}\text { Facilitation variable; fraction of available sites activated by } \\
\text { a stimulus }\end{array}$ \\
\hline$D$ & Depression variable; fraction of sites that are release-ready \\
\hline$p_{\mathrm{R}}$ & Probability of release; product of the probabilities F and D \\
\hline$F_{1}$ & Initial probability of release \\
\hline$K_{\mathrm{F}}$ & Affinity of $C a X_{\mathrm{F}}$ for the release site \\
\hline$K_{\mathrm{D}}$ & Affinity of $C a X_{\mathrm{D}}$ for the release site \\
\hline$\tau_{\mathrm{F}}$ & Decay time constant of $C a X_{\mathrm{F}}$ after an action potential \\
\hline$\tau_{\mathrm{D}}$ & Decay time constant of $\mathrm{CaX}$ D after an action potential \\
\hline$\Delta_{\mathrm{F}}$ & Incremental increase in $C a X_{\mathrm{F}}$ after a stimulus \\
\hline$\Delta_{\mathrm{D}}$ & Incremental increase in $C a X_{\mathrm{D}}$ after a stimulus \\
\hline$k_{\mathrm{o}}$ & Baseline rate of recovery from the refractory state \\
\hline$k_{\max }$ & Maximal recovery rate from the refractory state \\
\hline$\rho$ & Facilitation ratio $\mathrm{EPSC}_{2} / \mathrm{EPSC}_{1}$ for closely spaced EPSCs \\
\hline$N_{\mathrm{T}}$ & Total number of release sites \\
\hline$\alpha$ & Average mEPSC size \\
\hline
\end{tabular}
and $\tau_{\mathrm{D}}$ instead of $\tau_{\mathrm{c}}$ for the decay time constant of this species. The model assumes three possible states of the release apparatus $(R, T$, and $N)$, where $R$ sites are in a refractory state, $T$ are in a transitional state, qj $N$ sites are release-ready, and there are a total of $N_{\mathrm{T}}$ release sites $\left(R+T+N=N_{\mathrm{T}}\right)$.

Calcium dependence of the recovery rate $(R \rightarrow N)$ was captured by the equilibrium binding occupancy of a calcium-bound molecule $C a X_{\mathrm{D}}$,
Table 1. Definitions of parameters used in the FD model

which instantaneously rises by $\Delta_{\mathrm{D}}$ after an action potential at time $t_{\mathrm{o}}$ and decays to 0 exponentially with time constant $\tau_{\mathrm{D}}$ :

$$
\frac{d C a X_{\mathrm{D}}}{d t}=-\operatorname{Ca} X_{\mathrm{D}}(t) / \tau_{\mathrm{D}}+\Delta_{\mathrm{D}} \cdot \delta\left(t-t_{\mathrm{o}}\right)
$$

This treatment approximates the underlying kinetics of a reaction between $\mathrm{Ca}_{\text {res }}$ and some site $X_{\mathrm{D}}$ in a manner similar to the facilitation scheme described above. Experimentally, the value of $\tau_{\mathrm{D}}$ was estimated from the amplitude and duration of the rapid phase of recovery from paired-pulse depression at the climbing fiber synapse at $34^{\circ} \mathrm{C}$ [see Dittman and Regehr (1998) for a similar approach at $24^{\circ} \mathrm{C}$ ]. Because $\tau_{\mathrm{F}}$ and $\tau_{\mathrm{D}}$ reflect distinct binding reactions, there is no a priori reason to assume that they will have equal values. As explained in Results, we found that the experimental data could be better fit using a value of $\tau_{\mathrm{D}}$ that was about half the value of $\tau_{\mathrm{F}}$, perhaps reflecting different underlying calcium-binding kinetics.

The probability that a release site is release-competent is then given by the depression variable $D=N / N_{\mathrm{T}}$, governed by the equation:

$$
\frac{d D}{d t}=(1-D(t)) \cdot k_{\text {recov }}\left(C a X_{\mathrm{D}}\right)-D(t) \cdot F(t) \cdot \delta\left(t-t_{\mathrm{o}}\right),
$$

where

$$
k_{\text {recov }}\left(C a X_{\mathrm{D}}\right)=\frac{k_{\text {max }}-k_{\mathrm{o}}}{1+K_{\mathrm{D}} / \operatorname{CaX}(t)}+k_{\mathrm{o}} .
$$

For Equations 12 and 13, rapid equilibration with $C a X_{\mathrm{D}}$ and the steadystate approximation $d T / d t \approx 0$ are assumed as described previously (Dittman and Regehr, 1998). For $C a X_{\mathrm{D}}=0, k_{\text {recov }}=k_{\mathrm{o}}$, and $D$ recovers exponentially with time constant $\tau_{\text {recov }}=1 / k_{\mathrm{o}}$. For values of $C a X_{\mathrm{D}} \gg K_{\mathrm{D}}$, $k_{\text {recov }}=k_{\text {max }}$, so $D$ recovers exponentially at a faster rate with $\tau_{\text {recov }} \approx$ $1 / k_{\max }$. For intermediate, time-varying values of $\mathrm{CaX}$ D,$D$ recovers with both fast and slow kinetic components. The form of Equation 14 was chosen for mathematical convenience as in Equation 2a. With this form of rate dependence, $\mathrm{CaX}_{\mathrm{D}}$ is allowed to decay to 0 while the rate of recovery slows to a fixed, calcium-independent rate.

For regular stimulus trains given at frequency $r$, Equations 12, 13, and 14 can be used to generate an analytical expression for the fraction of available release sites during the $i$ th stimulus:

$$
D_{\mathrm{i}}(r)=1-\left(1-\left(1-F_{\mathrm{i}-1}(r)\right) \cdot D_{\mathrm{i}-1}(r)\right) e^{-k_{\mathrm{o}} / r} \cdot \xi_{\mathrm{i}}(r),
$$

where

$$
\xi_{\mathrm{i}}(r)=\left(\frac{K_{\mathrm{D}} / \operatorname{CaX} X_{\mathrm{D}_{\mathrm{i}-1}}+1}{K_{\mathrm{D}} / C a X_{\mathrm{D}_{\mathrm{i}-1}}+\exp \left(-1 / r \tau_{\mathrm{D}}\right)}\right)^{-\left(k_{\max }-k_{\mathrm{o}}\right) \tau_{\mathrm{D}}} .
$$


$\mathrm{CaX} X_{\mathrm{Di}-1}$ is the level of calcium-bound $X_{\mathrm{D}}$ just after the $(i-1)$ th stimulus and is given by:

$$
\operatorname{CaX} X_{\mathrm{D}_{\mathrm{i}-1}}(r)=\operatorname{CaX} X_{\mathrm{D}_{\boldsymbol{s}}}(r) \cdot\left[1-\exp \left(-(i-1) / r \tau_{\mathrm{D}}\right)\right],
$$

where:

$$
\operatorname{CaX}_{\mathrm{D}_{\infty}}(r)=\Delta_{\mathrm{D}} \cdot\left[1-\exp \left(-1 / r \tau_{\mathrm{D}}\right)\right]^{-1} .
$$

For the $i$ th stimulus in a regular train of rate $r$, the normalized $\mathrm{EPSC}_{\mathrm{i}}$ can be expressed analytically:

$$
\frac{E P S C_{\mathrm{i}}(r)}{E P S C_{1}}=\frac{\alpha \cdot N_{\mathrm{T}} \cdot D_{\mathrm{i}}(r) \cdot F_{\mathrm{i}}(r)}{\alpha \cdot N_{\mathrm{T}} \cdot D_{1} \cdot F_{1}}=D_{\mathrm{i}}(r) \cdot\left(F_{\mathrm{i}}(r) / F_{1}\right) .
$$

During a prolonged stimulus train, the number of available sites reaches a steady-state value that can be expressed analytically using Equations 9, $11,15,16$, and 18:

$$
D_{\infty}(r)=\frac{1-\exp \left(-k_{\mathrm{o}} / r\right) \cdot \xi_{\infty}(r)}{1-\left(1-F_{\infty}(r)\right) \exp \left(-k_{\mathrm{o}} / r\right) \cdot \xi_{\infty}(r)} .
$$

Combining this equation with Equation 11, one can then generate an analytical expression for the steady-state EPSC size normalized to the initial EPSC:

$$
\frac{\operatorname{EPSC}_{\infty}(r)}{\operatorname{EPSC}_{1}}=D_{\infty}(r) \cdot\left(F_{\infty}(r) / F_{1}\right) .
$$

Equations 19 and 21 were used to generate the simulations in Figures 3-6. Simulated EPSC waveforms were produced using the normalized alpha function, $\left(t^{*} e / \tau_{\mathrm{E}}\right)^{*} \exp \left(-t / \tau_{\mathrm{E}}\right)$ where $\tau_{\mathrm{E}}$ was the decay time constant of the simulated EPSC. The alpha function was then scaled in amplitude to the value $\mathrm{EPSC}_{\mathrm{i}}$ for the $i$ th EPSC in a train:

$$
\operatorname{EPSC}_{\mathrm{i}}(t)=\alpha \cdot N_{\mathrm{T}} \cdot D_{\mathrm{i}} \cdot F_{\mathrm{i}} \cdot\left(t \cdot e / \tau_{\mathrm{E}}\right) \cdot \exp \left(-t / \tau_{\mathrm{E}}\right) .
$$

For the synapses modeled in this study, $\tau_{\mathrm{E}}$ was set equal to $2 \mathrm{msec}$. For the Poisson train simulations in Figure 7, Equations 10 and 15 were used with $C a X_{\mathrm{Fi}}$ and $C a X_{\mathrm{Di}}$ generated by the recursive equations:

$$
\begin{aligned}
& C a X_{\mathrm{F}_{\mathrm{i}}}=C a X_{\mathrm{F}_{\mathrm{i}-1}} \cdot \exp \left[-\left(\Delta t_{\mathrm{i}}\right) / \tau_{\mathrm{F}}\right], \\
& C a X_{\mathrm{D}_{\mathrm{i}}}=C a X_{\mathrm{D}_{\mathrm{i}-1}} \cdot \exp \left[-\left(\Delta t_{\mathrm{i}}\right) / \tau_{\mathrm{D}}\right],
\end{aligned}
$$

where $\Delta \mathrm{t}_{\mathrm{i}}$ is the $i$ th inter-stimulus interval in a Poisson train. A summary of the model parameters is given in Table 1 .

Simulated integrate-and-fire neuron. For Figure 8, we implemented a single compartment model neuron with membrane time constant $\tau_{\mathrm{m}}=20$ msec, input resistance $R_{\mathrm{N}}=100 \mathrm{M} \Omega$, and resting potential $V_{\text {rest }}=-70$ $\mathrm{mV}$. The EPSC waveforms generated with Equation 22 were then scaled to conductance values, $G_{\text {syn }}(t)$, chosen to produce a particular EPSP magnitude (see Fig. 8) with synaptic reversal potential $V_{\text {syn }}$ set equal to $0 \mathrm{mV}$. Membrane voltage $\left(V_{\mathrm{m}}\right)$ was determined by solving the first-order differential equation:

$$
\tau_{\mathrm{m}} \frac{d V_{\mathrm{m}}}{d t}=G_{\mathrm{syn}}(t) \cdot R_{\mathrm{N}} \cdot\left(V_{\mathrm{syn}}-V_{\mathrm{m}}\right)+\left(V_{\text {rest }}-V_{\mathrm{m}}\right),
$$

where if the voltage exceeded threshold $\left(V_{\text {thresh }}=-55 \mathrm{mV}\right)$, its value was then jumped to +40 for $1 \mathrm{msec}$ and then hyperpolarized to $-75 \mathrm{mV}$ using an idealized action potential waveform template. For Figure 8, Equation 25 was numerically integrated with a first-order Euler routine.

\section{RESULTS}

We recorded synaptic currents during various stimulus conditions at three CNS synapses in rat brain slices. In addition, presynaptic calcium influx was measured in cerebellar granule cell presynaptic terminals for the same stimulus conditions. These experimental studies formed the basis of a model of synaptic plasticity that was then applied to each type of synapse.

\section{Diversity of short-term synaptic plasticity in the CNS}

The responses of three types of synapses to $50 \mathrm{~Hz}$ stimulation were measured using whole-cell voltage clamp at $34^{\circ} \mathrm{C}$ (Fig. $2 A$ ). The inferior olive climbing fiber to Purkinje cell synapse (CF)
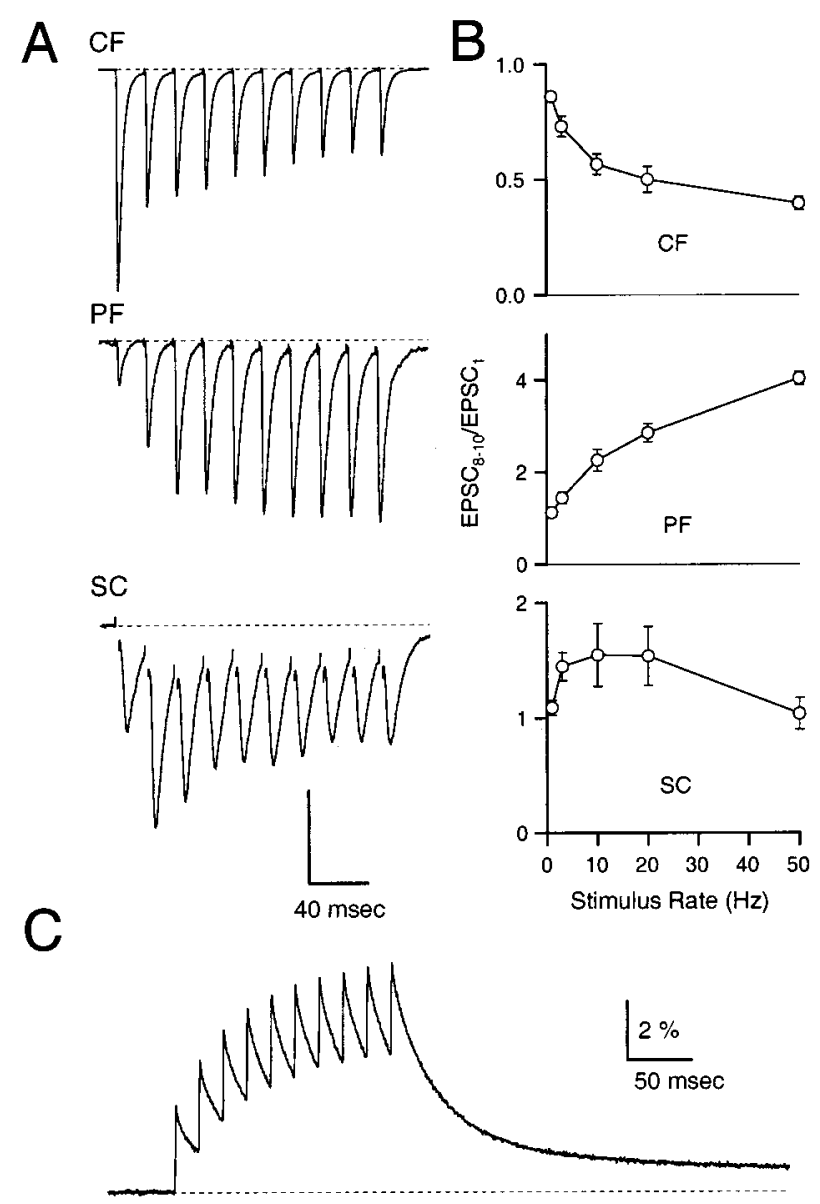

Figure 2. Diversity of short-term plasticity in the CNS. A, Top, Climbing fiber to Purkinje cell EPSCs $(C F)$; middle, parallel fiber to Purkinje cell EPSCs $(P F)$; bottom, CA3 to CA1 Schaffer collateral EPSCs $(S C)$ recorded while stimulating afferents at $50 \mathrm{~Hz}$ for 10 stimuli at $34^{\circ} \mathrm{C}$. Traces are averages of four to six trials each. Stimulus artifacts were suppressed for clarity. Vertical scale bar is 2, 400, and $60 \mathrm{pA}$ for the CF, PF, and SC synapses, respectively. $B$, Average magnitude of the 8th-10th EPSC normalized by the first EPSC plotted as a function of stimulus frequency for the climbing fiber (top), the parallel fiber (middle), and the Schaffer collateral (bottom) synapses. Data are shown as mean \pm SEM $(n=4-5)$. $C$, Measurement of parallel fiber $\mathrm{Ca}_{\text {res }}$ during a 10 pulse, $50 \mathrm{~Hz}$ stimulus train using the calcium-sensitive indicator magnesium green. Vertical scale bar is percentage $\Delta F / F$. Parallel fiber data were adapted from Kreitzer and Regehr (2000).

depressed during stimulus trains as reported previously (Fig. $2 A$, top trace) (Eccles et al., 1966). The cerebellar granule cell parallel fiber to Purkinje cell synapse (PF) was activated under stimulus conditions identical to those of the climbing fiber synapse (Fig. $2 A$, middle trace) but synaptic strength enhanced markedly during the stimulation. In contrast to the previous examples, the hippocampal CA3 to CA1 Schaffer collateral synapse (SC) briefly facilitated and then depressed during the stimulus train. These three synapses demonstrate the wide spectrum of short-term transmitter release properties expressed during high-frequency stimulation.

For all three synapses, the immediate effects of short-term plasticity began to plateau by the eighth stimulus. Therefore, the normalized average of EPSCs 8 through $10\left(\mathrm{EPSC}_{8-10} /\right.$ EPSC $_{1}$ ) provided a useful measure of steady-state behavior. The frequency-dependence of steady-state transmitter release clearly differed at each type of synaptic connection (Fig. 2B). 
The climbing fiber depressed and the parallel fiber facilitated at all frequencies. The Schaffer collateral synapse facilitated at low rates but depressed during higher-frequency stimulation. During prolonged stimuli, processes acting on the tens of seconds to minutes time scale, such as post-tetanic potentiation and a slower form of presynaptic depression (Galarreta and Hestrin, 1998), could potentially affect release. Thus, stimulus trains were kept relatively short to isolate facilitation and shorter-lived forms of depression.

In addition to quantifying transmitter release, we recorded the behavior of $\mathrm{Ca}_{\text {res }}$ during high-frequency stimulation (see Materials and Methods). A representative measurement of granule cell $\mathrm{Ca}_{\text {res }}$ during a 10 stimulus $50 \mathrm{~Hz}$ train using the calcium-sensitive indicator magnesium green is shown in Figure $2 C . \mathrm{Ca}_{\text {res }}$ increased rapidly after each stimulus and then decayed over hundreds of milliseconds with a time course that is similar in many synapses in the CNS (Feller et al., 1996; Helmchen et al., 1997; Sinha et al., 1997).

\section{A model of presynaptic plasticity}

We developed a model to account for the behavior of these synapses during repetitive stimulation. Our aim was to keep the model as simple as possible while including a level of detail matched to the constraints provided by our experiments. A number of simplifying assumptions allowed us to obtain an analytical solution while retaining important aspects of facilitation and recovery from depression. According to our scheme, sustained presynaptic activity depletes the number of functional sites but also elevates $\mathrm{Ca}_{\text {res }}$, thereby facilitating release and accelerating recovery from depression (Fig. $3 A$ ). The model is based on the following principles:

\section{Assumption I}

Release $=N_{\mathrm{T}} \cdot p_{\mathrm{R}}$ where $N_{\mathrm{T}}$ is the number of physical release sites and $p_{\mathrm{R}}$ is the probability of transmitter release (Del Castillo and Katz, 1954a).

\section{Assumption II}

Release probability is composed of two independent variables (probabilities): $p_{\mathrm{R}}=F \cdot D$ where $F$ and $D$ both range between 0 and 1 . Therefore, the average EPSC is given by $\alpha \cdot N_{\mathrm{T}} \cdot F \cdot D$ where $\alpha$ is the average mEPSC amplitude (Eq. 1). The values of $F$ and $D$ determine the state of the presynaptic terminal. Although $F$ and $D$ are thought to be stochastic variables at individual release sites, we treated them as deterministic averages in this study for the purpose of simplicity (Del Castillo and Katz, 1954b; Stevens and Wang, 1995). In this way, "release" represents the average of many trials at a particular synaptic connection, or equivalently the summation of many simultaneously activated synapses.

\section{Assumption III}

Facilitation is attributable to the calcium-dependent increase in the value of $F$ from an initial value $F_{1}$ according to the fractional occupancy of some calcium-bound molecule $C a X_{\mathrm{F}}$ at the release site (Fig. $3 A, B$, left). $C a X_{\mathrm{F}}$ increases by a constant amount $\left(\Delta_{\mathrm{F}}\right)$ with each action potential and decays exponentially toward 0 with time constant $\tau_{\mathrm{F}}$ (Eqs. 2, 2a, and 3). A constant increment in $C a X_{\mathrm{F}}$ is equivalent to assuming that $X_{\mathrm{F}}$ remains unsaturated during a stimulus train.

\section{Assumption IV}

Depression is determined by the fraction of sites that undergoes transmitter release in such a way that $D=$ (number of available
A
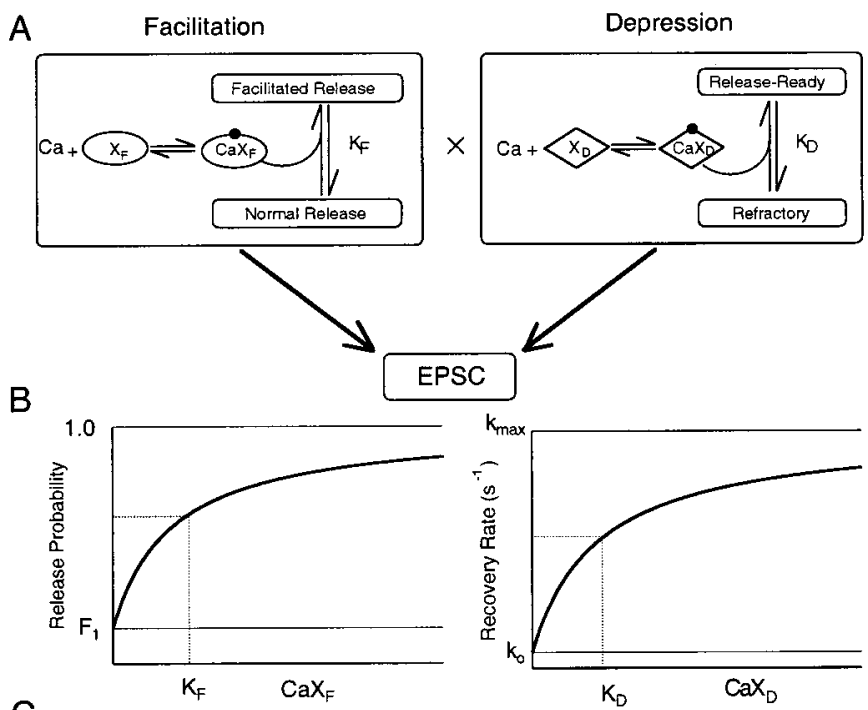

C
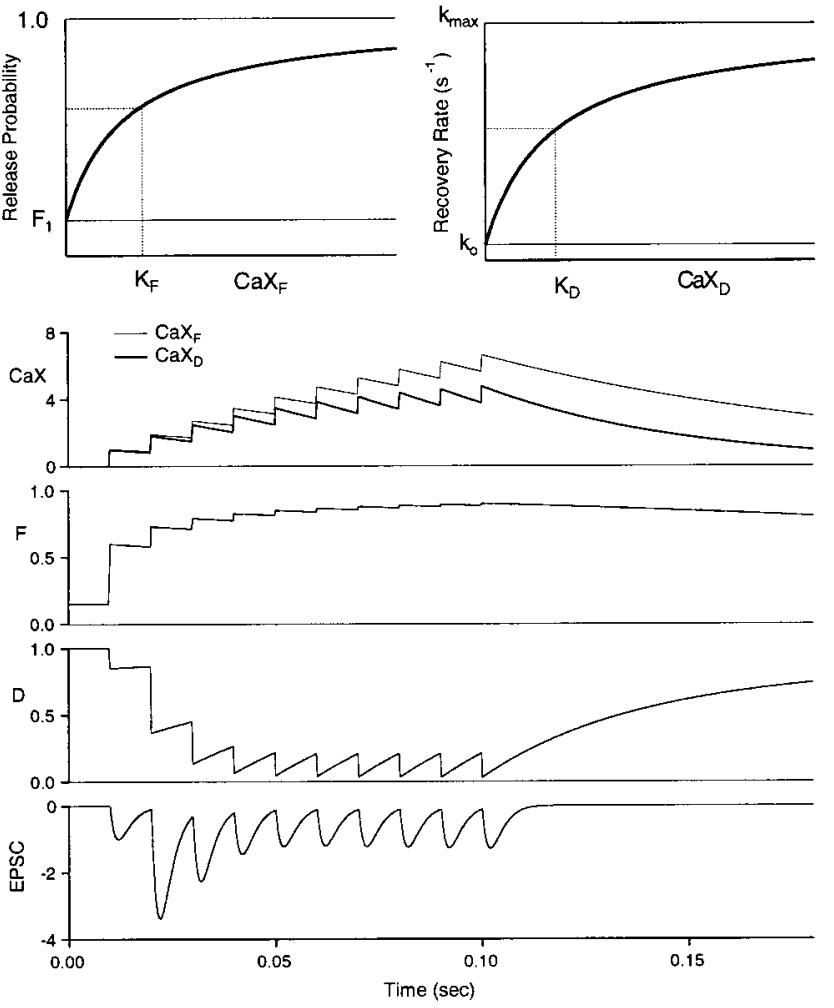

Figure 3. FD model for Ca-dependence of short-term plasticity. $A$, Left, Residual presynaptic calcium binds to site $X_{\mathrm{F}}$, and the complex $\mathrm{CaX}_{\mathrm{F}}$ then binds to the release site causing an enhancement of release probability. Right, Schematic of residual presynaptic calcium binding to site $X_{\mathrm{D}}$, which then binds with the refractory release site driving a transition back to the release-ready state. $B$, Left, $F$ plotted as a function of $C a X_{\mathrm{F}}$ ranging from a minimal probability of $F_{1}$ (no residual calcium) to a maximum of 1 . The dissociation constant for $C a X_{\mathrm{F}}$ is $K_{\mathrm{F}}$. Right, the recovery rate for depression is plotted as a function of $\operatorname{CaX}_{\mathrm{D}}$ with a minimum rate of $k_{\mathrm{o}}$, a maximum rate of $k_{\max }$, and $\operatorname{CaX} X_{\mathrm{D}}$ dissociation constant $K_{\mathrm{D}} . C$, Presynaptic levels of $\mathrm{CaX}_{\mathrm{F}}$ (thin line) and $\mathrm{CaX}_{\mathrm{D}}$ (thick line), fraction of available synapses that undergo release $(F)$, fraction of release-ready synapses $(D)$, and normalized EPSC during a train of 10 stimuli at $100 \mathrm{~Hz}$. Model parameters for this simulation were $\rho=3.4, F_{1}=0.15, \tau_{\mathrm{F}}=100 \mathrm{msec}, \tau_{\mathrm{D}}=50 \mathrm{msec}$, $k_{\max }=30 \mathrm{sec}^{-1}, k_{\mathrm{o}}=2 \mathrm{sec}^{-1}, K_{\mathrm{D}}=2$. Note that $\operatorname{CaX}_{\mathrm{F}}$ and $\operatorname{CaX}_{\mathrm{D}}$ were normalized to their respective dissociation constants.

sites)/(total number of sites). According to Assumptions I and II, $N_{\mathrm{T}}{ }^{*} F_{1}{ }^{*} D_{1}$ sites have undergone transmitter release and enter a refractory state, leaving $N_{\mathrm{T}}{ }^{*}\left(1-F_{1}{ }^{*} D_{1}\right)$ sites available to release immediately afterward. Therefore $D_{2}=1-F_{1}{ }^{*} D_{1}$ just after an action potential and recovers back to $D_{1}$ at a specified rate (see assumption V). For maximal simplicity in the model we explore here, it was assumed that $D_{1}=1$ (i.e., after long quiescent intervals, all sites are available to undergo release; see Eqs. 5 and 
6). We refer to this form of depression as refractory depression [see also Dittman and Regehr (1998)].

\section{Assumption $V$}

Recovery from refractory depression is dependent on $\mathrm{Ca}_{\text {res }}$ in the following manner. In the absence of $\mathrm{Ca}_{\text {res }}$, recovery proceeds at some minimal rate $k_{\mathrm{o}}$. After a stimulus, the rate is accelerated by the interaction of a calcium-bound molecule $\mathrm{CaX}_{\mathrm{D}}$ with the release site (Fig. $3 A$, right, and Eqs. 12, 13, and 14). $C a X_{\mathrm{D}}$ increases by a constant amount $\Delta_{\mathrm{D}}$ and decays exponentially to 0 with a time constant $\tau_{\mathrm{D}}$. We refer to this calcium-dependent acceleration of recovery from refractory depression as CDR. This treatment is based on our studies at the climbing fiber synapse (Dittman and Regehr, 1998). As in the case of $X_{\mathrm{F}}$, we assume that $X_{\mathrm{D}}$ is not saturated during stimulus trains (see assumption III).

\section{Assumption VI}

Facilitation and depression are inherently coupled through assumptions I, II, and III. As facilitation increases the number of sites that undergo release, a larger fraction of the total number of sites enters the refractory state, thereby increasing depression. $\tau_{\mathrm{F}}$ was estimated by the decay of paired-pulse facilitation at the parallel fiber to Purkinje cell synapse (Fig. 3B) (Atluri and Regehr, 1996). $\tau_{\mathrm{D}}$ was estimated as in Dittman and Regehr (1998). The values of $\tau_{\mathrm{F}}$ and $\tau_{\mathrm{D}}$ are set in part by the decay of $\mathrm{Ca}_{\text {res }}$, so changes in $\mathrm{Ca}_{\text {res }}$ will perturb the recovery kinetics of both facilitation and depression (Eqs. 15 and 16).

An example of the proposed model is shown in Figure $3 C$ during a 10 pulse $100 \mathrm{~Hz}$ stimulus train. The details of the model are described in Materials and Methods. During the train, $\mathrm{Ca}_{\text {res }}$ and the calcium-bound species $C a X_{\mathrm{F}}$ and $C a X_{\mathrm{D}}$ build up and then decay with their characteristic time constants. $F$ is initially 0.15 and increases approximately fivefold during the train. Because the $C a X_{\mathrm{F}}$ binding sites are nearly saturated after 10 stimuli, $F$ increases toward unity and remains elevated after free $C a X_{\mathrm{F}}$ decays toward $0 . D$ quickly declines during the train, but recovery from the refractory state accelerates as $C a X_{\mathrm{D}}$ reaches a high concentration. As a result of the increase in $F$ and the decrease in $D$, transmitter release first enhances and then declines during the stimulus train. The EPSCs shown in Figure $3 C$ are scaled to reflect the product $F \cdot D$ normalized to the initial value $F_{1}$ (see Materials and Methods).

\section{Categories of synaptic behavior arising from the facilitation-depression model}

We next explored the contributions of calcium-dependent processes to synaptic behavior simulated by the facilitation-depression (FD) model (Fig. 4). The four simulations shown here describe the same synapse in the presence or absence of either facilitation $( \pm \mathrm{Fac})$ or calcium-dependent recovery $( \pm \mathrm{CDR})$ during a $50 \mathrm{~Hz}$ stimulus train. In the absence of facilitation and CDR, sustained activity gradually depressed synaptic strength (Fig. $\left.4 A_{1}\right)$. The steady-state level of depression was more pronounced at higher stimulus frequencies (Fig. $4 A_{2}$ ). Thus, the synapse behaves as a low-pass filter during regular stimulus trains with little attenuation at frequencies below $1 \mathrm{~Hz}$, a frequency that corresponds to the slow recovery rate $\left(k_{\mathrm{o}}\right)$. Stimulation at higher frequencies eventually depletes a large fraction of available release sites because there is not sufficient time for recovery between stimuli.

When facilitation was added to this model synapse (+Fac, $-\mathrm{CDR}$ ), a strikingly different behavior emerged during the first

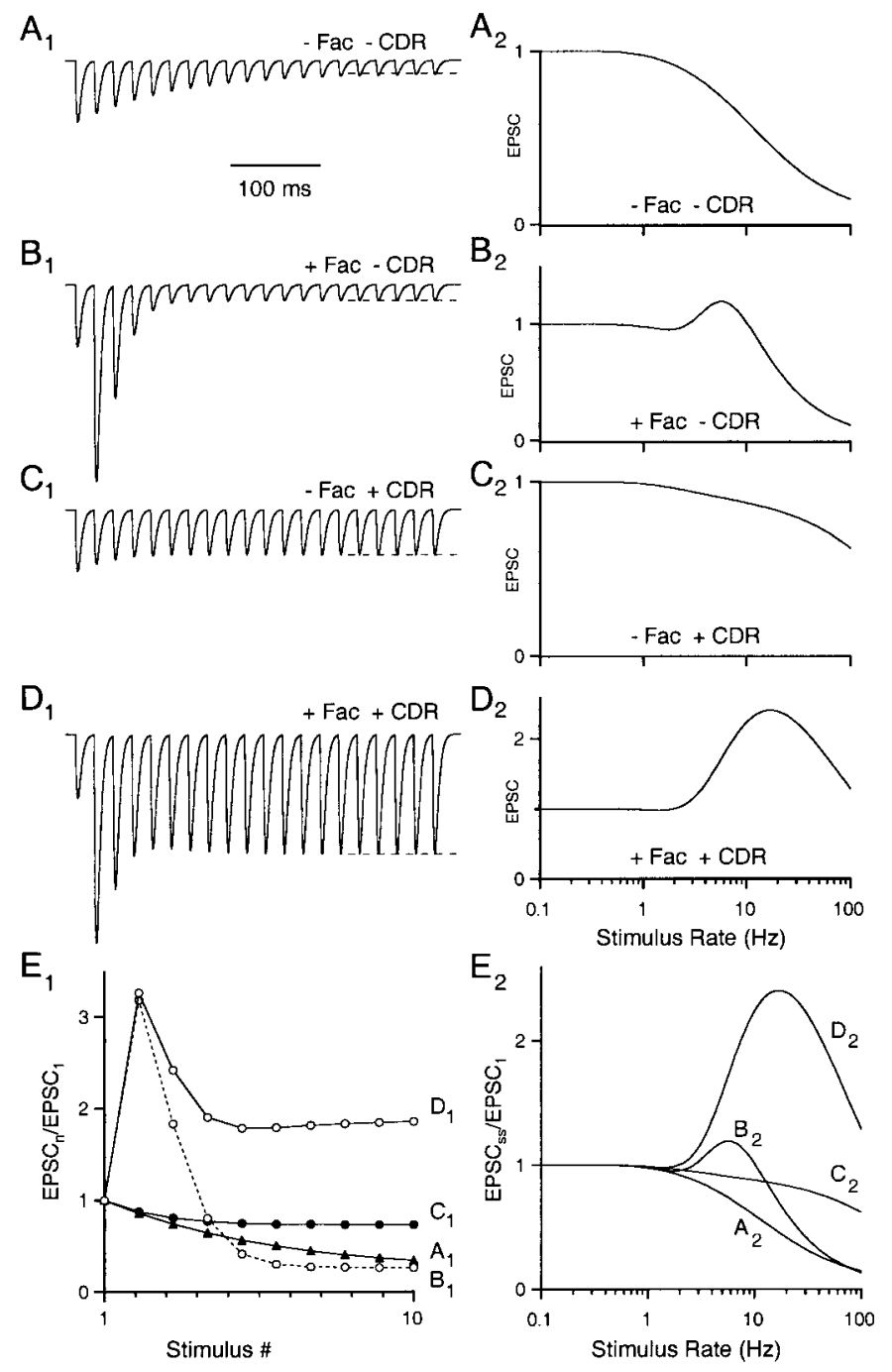

Figure 4. Effects of facilitation and CDR on presynaptic dynamics. $A_{1}$, Simulation of 20 EPSCs generated at $50 \mathrm{~Hz}$ in a reduced FD model with no facilitation or CDR. Dashed line represents the steady-state EPSC size. $A_{2}$, Steady-state EPSC magnitude (normalized to the first EPSC) as a function of stimulus frequency. $B$, Same as $A$ for a simulation with facilitation only. $C$, Same as $A$ for a simulation model with CDR only. $D$, Same as $A$ for a simulation with both facilitation and CDR. Equations 19 and 21 were used with model parameters from Figure 3. $E_{1}$, EPSC peak amplitudes versus stimulus number for the four model synapses. $E_{2}$, Steady-state EPSC versus frequency curves from $A_{2}$ to $D_{2}$ are superimposed. For $A$ and $C, F$ was held constant at $F_{1}$. For $A$ and $B$, the recovery rate was held constant at $k_{\mathrm{o}}$.

few stimuli (Fig. $4 B_{1}$ ). The EPSC amplitude transiently increased, reflecting an increase in $F$. However, the increasingly larger fraction of sites undergoing release rapidly depleted the number of available sites (decrease in $D$ ). After only five stimuli, transmitter release fell to similar levels as in the previous example, despite the presence of facilitation (Fig. $4 E_{1}$, traces $A$ and $B$ ). In the absence of facilitation, steady-state levels of transmitter release were reached after more than 10 stimuli. Thus, facilitation reduces the time to reach steady state according to the FD model. The similarity in steady-state behavior between these two cases can be seen more explicitly by comparing the superimposed frequency response curves (Fig. $4 E_{2}$, traces $A$ and $B$ ). The only difference between these two synapses at steady state is a boosting at intermediate frequencies $(\sim 3-10 \mathrm{~Hz})$. 


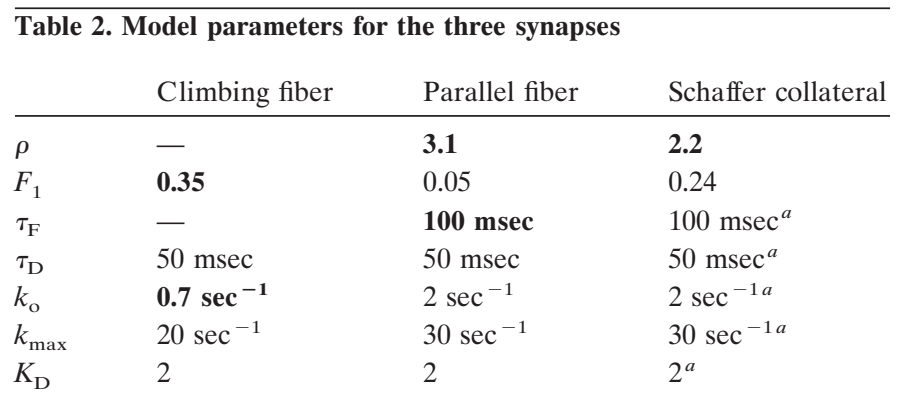

Parameter values in bold type were constrained from experimental values (see Results). Others are free parameters determined by fits to the data in Figure 5. $\rho$ and $\tau_{\mathrm{F}}$ were not included in the climbing fiber model.

${ }^{a}$ Parameters taken from fits to parallel fiber data.

For a nonfacilitating synapse, the inclusion of CDR (-Fac, $+\mathrm{CDR}$ ) allows the synapse to remain much more effective over a wide range of stimulus frequencies (Fig. $4 C$ ). As the stimulus frequency increases, $\mathrm{Ca}_{\text {res }}$ increases proportionally, boosting the recovery rate at high frequencies and maintaining synaptic efficacy even during prolonged trains (Fig. $4 E_{2}$, traces $A$ and $C$ ).

When facilitation and CDR are both present (+Fac, +CDR), two features become apparent (Fig. 4D). First, a transient increase in release is observed during the first few stimuli because of increases in $F$, similar to the (+Fac, $-\mathrm{CDR}$ ) synapse. Second, steady-state release was maximal at a stimulus frequency of $\sim 12$ $\mathrm{Hz}$. This tuning curve arises from an interplay between facilitation and depression. At low frequencies $(<1 \mathrm{~Hz})$, there is little $\mathrm{Ca}_{\text {res }}$ accumulation, and neither facilitation nor refractory depression influences transmitter release. At intermediate frequencies (5-20 Hz), release probability begins to increase, and the recovery rate from depression accelerates in concert leading to a net enhancement. Finally, at high stimulus frequencies $(>50 \mathrm{~Hz})$, release probability and recovery rate have saturated at their maximal values but the inter-stimulus interval is too short for a significant amount of recovery to occur, so synaptic strength falls off precipitously.

The transient and steady-state responses of all four simulated synapses are superimposed in Figure $4 E$. Steady-state synaptic strength is identical for these synapses at stimulus rates $<1 \mathrm{~Hz}$ because little if any $\mathrm{Ca}_{\text {res }}$ accumulates for long inter-stimulus intervals $(>1 \mathrm{sec})$. The divergence in steady-state behavior observed at higher frequencies arises from recruitment of the calcium-dependent processes described above. Thus, the decay kinetics of $\mathrm{Ca}_{\text {res }}$ determine a frequency threshold, below which facilitation and CDR do not influence synaptic strength.

\section{Fitting the FD model to three synapses}

After characterizing some of the basic features of the FD model, we determined whether it could account for the observed behavior of the climbing fiber, parallel fiber, and Schaffer collateral synapses studied above. We began by establishing experimentally based values for many of the FD model parameters (Table 2). At the climbing fiber synapse, $F_{1}$ was set by the amount of pairedpulse depression (35\%) for two closely spaced stimuli. $k_{\mathrm{o}}$ was estimated from the recovery time course at long inter-stimulus intervals (Dittman and Regehr, 1998). For the parallel fiber synapse, the decay of $\mathrm{CaX}_{\mathrm{F}}\left(\tau_{\mathrm{F}}\right)$ was constrained to match the decay of paired-pulse facilitation, and the amplitude of facilitation determined the value of $\rho$ (Atluri and Regehr, 1996). For the Schaffer collateral synapse, only the amount of facilitation $(\rho)$ was experimentally determined. To constrain the SC model further,

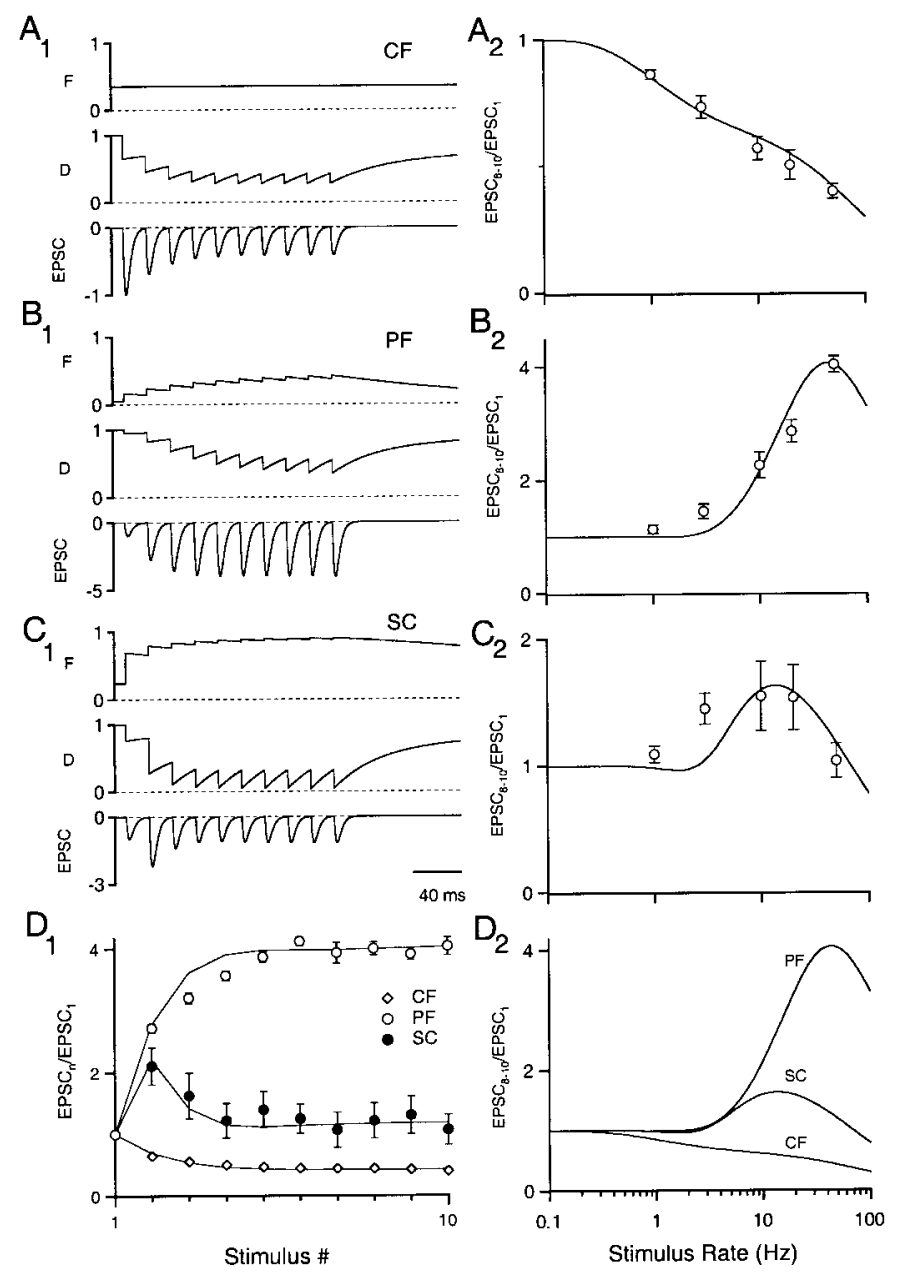

Figure 5. Application of the FD model to real synapses. $A_{1}, \mathrm{~F}, \mathrm{D}$, and EPSC size during a 10 pulse $50 \mathrm{~Hz}$ stimulus train for a model climbing fiber to Purkinje cell synapse. $A_{2}$, Amplitude of the 8th-10th EPSC (taken from Fig. $2 B$ ) plotted against stimulus frequency. Solid line is the analytical solution given in Equation 21. Model parameters were $F_{1}=$ 0.35 for $A_{1}, \tau_{\mathrm{D}}=50 \mathrm{msec}, k_{\max }=20 \mathrm{sec}^{-1}, k_{\mathrm{o}}=0.7 \mathrm{sec}^{-1}, K_{\mathrm{D}}=2 . B_{1}$, $B_{2}$, Same as $A$ for the parallel fiber to Purkinje cell synapse. Model parameters for both $B_{1}$ and $B_{2}$ were $\rho=3.1, F_{1}=0.05, \tau_{\mathrm{F}}=100 \mathrm{msec}$, $\tau_{\mathrm{D}}=50 \mathrm{msec}, k_{\max }=30 \mathrm{sec}^{-1}, k_{\mathrm{o}}=2 \mathrm{sec}^{-1}, K_{\mathrm{D}}=2 . C_{1}, C_{2}$, Same as $A$ for the CA3 to CA1 Schaffer collateral synapse. Model parameters were $\rho=2.2, F_{1}=0.24$ for $C, \tau_{\mathrm{F}}=100 \mathrm{msec}, \tau_{\mathrm{D}}=50 \mathrm{msec}, k_{\max }=30 \mathrm{sec}^{-1}$, $k_{\mathrm{o}}=2 \mathrm{sec}^{-1}, K_{\mathrm{D}}=2 . D_{1}$, Normalized average EPSC magnitude during a $50 \mathrm{~Hz}$ stimulus versus stimulus number. Open circles represent mean EPSC amplitudes during $50 \mathrm{~Hz}$ trains plotted against stimulus number for the climbing fiber $(C F)$, parallel fiber $(P F)$, and Schaffer collateral $(S C)$ synapses. Data are mean \pm SEM with $n=5-7 . D_{2}$, FD model fits to the steady-state data in $A_{2}-C_{2}$ superimposed for comparison.

we assigned all parameters $\left(\tau_{\mathrm{F}}, \tau_{\mathrm{D}}, k_{\mathrm{o}}, k_{\max }\right.$, and $\left.K_{\mathrm{D}}\right)$ to the values used in the parallel fiber simulations except for the initial release probability, $F_{1}$. Table 2 summarizes the FD model parameter values used to characterize all three synapses. The values in bold were determined by experiments at $34^{\circ} \mathrm{C}$. Note that the parameter values differ from those reported in a previous study conducted at $24^{\circ} \mathrm{C}$ (Dittman and Regehr, 1998). The other values were chosen both "by eye" and with a least-squares minimization procedure. The predicted EPSC peaks and steady-state frequency curves shown in Figure 5 were generated by analytical solutions to approximations of Equations 3, 13, and 14 (see Materials and Methods, Eqs. 15-21 for analytical solutions). 
At the climbing fiber synapse, this model provided a reasonably good description of both the time course and frequencydependence of depression (Fig. $5 A_{2}, D_{1}$ ). Because no facilitation was observed at this synapse, $F$ was held constant for these simulations at $\sim 0.35$. This fixed value of $F$ implies that $35 \%$ of available sites release neurotransmitter when stimulated. The data were well approximated with only three free parameters (Table 2).

The model also captured the basic features of synaptic plasticity at the parallel fiber synapse (Fig. $5 B_{2}, D_{1}$ ). According to this simulation, the enhancement reflected a large increase in $F$ from an initial value of $\sim 0.05$ that was partially countered by a decrease in $D$. By the end of the train, the fourfold enhancement in release was the result of an eightfold increase in $F$ and a twofold reduction in $D$. Simulations of the hippocampal Schaffer collateral synapse were similar to the parallel fiber synapse (Fig. $5 C_{2}, D_{1}$ ), but the initial release probability was about five times as large (0.24). During the train, $F$ was close to unity (saturation of $C a X_{\mathrm{F}}$ binding sites), leading to a large reduction in $D$. The model could not account entirely for the enhancement of release observed at $3 \mathrm{~Hz}$ at either the parallel fiber or Schaffer collateral synapses (see Discussion). The model fits to steady-state release are superimposed in Figure $5 D_{2}$ for comparison. Despite the many simplifying assumptions that we made, the model accounts for synaptic dynamics during high-frequency stimulation fairly well at these three synapses.

\section{Possible role for CDR at "low P" synapses}

Calcium-dependent recovery from depression can play an important role in sustaining transmitter release during high rates of presynaptic activity. The importance of CDR has been demonstrated for synapses with high release probabilities where depression is prominent (Dittman and Regehr, 1998; Wang and Kaczmarek, 1998). However, CDR is more difficult to assess at low probability synapses such as the parallel fiber synapse, where facilitation tends to obscure any underlying depression. We used the FD model to explore a possible role of CDR in transmission at parallel fiber synapses (Fig. 6). During $50 \mathrm{~Hz}$ 25-pulse stimulation, the parallel fiber synapse reaches a steady-state level of facilitation with no sign of depression. In the absence of CDR with only slow calcium-independent recovery from depression present, the FD model did not predict a significant amount of steady-state facilitation (Fig. $6 A, \bullet$ ).

We investigated several possible explanations for the sustained enhancement observed in Figure 6 . One possibility is that an extremely low initial release probability $\left(F_{1}\right)$ can account for the apparent lack of depression during a train. However, we were unable to fit the data in Figure 5 with values of $F_{1}$ smaller than $\sim 0.05$ (data not shown), suggesting that simply lowering $F_{1}$ cannot explain the enhancement. Alternatively, recovery from depression could be fast enough to prevent most of the release sites from accumulating in the refractory state. This may reflect a fast basal rate of recovery $\left(k_{\mathrm{o}}\right)$ at the parallel fiber synapse (fit not shown) or a calcium-dependent acceleration of recovery from depression, as observed at the climbing fiber synapse. The FD model provided a good approximation to synaptic strength when the properties of recovery from depression were similar to those observed at the climbing fiber synapse, in that a slow component of recovery from depression and CDR were both present (Fig. 6A, ○).

These simulations emphasize that rapid recovery from depression may be important even at synapses with low initial release

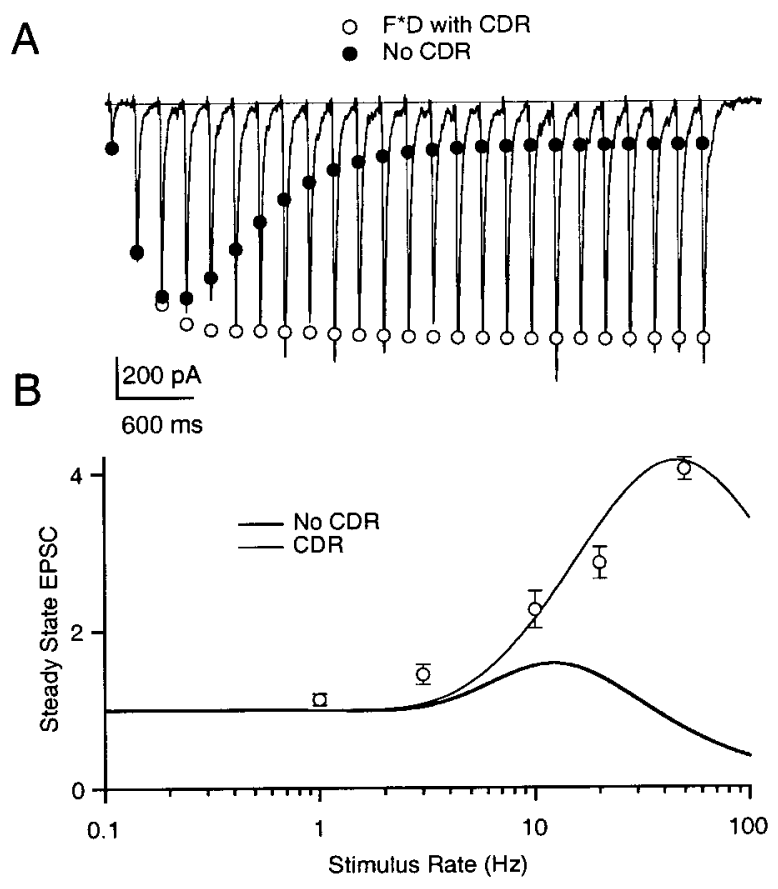

Figure 6. Importance of CDR at "low P" synapses. $A$, Parallel fiber to Purkinje cell EPSCs recorded during 25 stimuli at $50 \mathrm{~Hz}$. Trace represents a single trial. Open circles are the predicted FD model EPSC magnitudes using Equation 19. Filled circles represent the same FD model without CDR $\left(C a X_{\mathrm{D}}=0\right) . B$, Steady-state EPSC size plotted against stimulus frequency for the parallel fiber synapse with (thin line) and without (thick line) CDR. Open circles are parallel fiber data from Figure $2 B$. Model parameters were $\rho=3.8, F_{1}=0.038, \tau_{\mathrm{F}}=100 \mathrm{msec}, \tau_{\mathrm{D}}=50$ $\operatorname{msec}, k_{\max }=30 \mathrm{sec}^{-1}, k_{\mathrm{o}}=2 \mathrm{sec}^{-1}, K_{\mathrm{D}}=2$.

probabilities where depression is not apparent. The model suggests that fast recovery from depression is required to preserve synaptic strength during periods of prolonged activity. Without rapid recovery from depression, facilitating synapses cannot maintain significant enhancement at steady state. As shown in Figure 6, inclusion of CDR can account for the behavior of parallel fibers during long stimulus trains. However, further experiments are required to determine whether CDR is the mechanism responsible for fast recovery from depression at these synapses. This will be difficult to establish until the underlying molecular correlates of facilitation and CDR can be identified and independently manipulated.

\section{Synaptic plasticity during irregular stimulus trains}

As a further test of the FD model, synaptic currents were recorded at the climbing fiber, parallel fiber, and Schaffer collateral synapses during stimulation with irregular stimulus trains (Fig. 7). The climbing fiber synapse showed sustained depression during the train, with significant recovery after inter-spike intervals greater than a few hundred milliseconds (Fig. 7A, top). In contrast, the parallel fiber synapse facilitated during periods of highfrequency activity (Fig. $7 A$, middle). The Schaffer collateral synapse enhanced to a similar degree but the temporal pattern of EPSC peaks differed from the parallel fiber synapse (Fig. 7A, bottom). At all three synapses, there was a high degree of peakto-peak variability attributable in large part to the short-term plasticities described above.

The analytical FD model used in Figure 5 accounted for features of this EPSC variability as shown in Figure $7 B$. The 
A Experiment

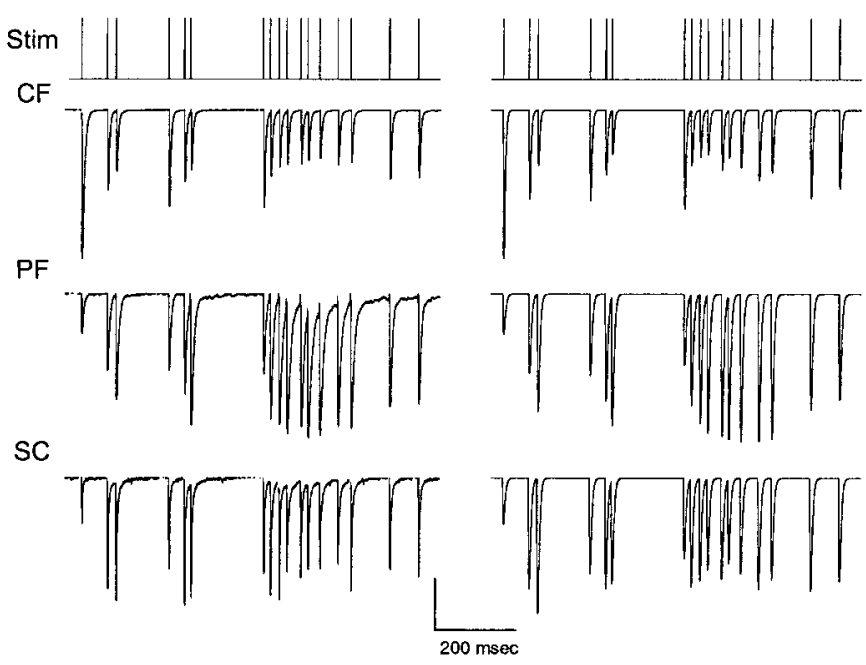

Figure 7. Presynaptic dynamics during Poisson stimulus trains. $A$, Examples of EPSCs recorded in response to an irregular stimulus train with average rate $20 \mathrm{~Hz}$ at the climbing fiber $(C F)$, parallel fiber $(P F)$, and Schaffer collateral $(S C)$ synapases. Stimulus artifacts were suppressed for clarity. $B, \mathrm{FD}$ model simulations for the three synapses. Vertical scale bar is 1,400 , and $200 \mathrm{pA}$ for the CF, PF, and SC synapses, respectively. Model parameters for CF were $F_{1}=0.57, \tau_{\mathrm{D}}=50 \mathrm{msec}, k_{\max }=30 \mathrm{sec}^{-1}, k_{\mathrm{o}}=$ $2 \mathrm{sec}^{-1}, K_{\mathrm{D}}=3.6$. Model parameters for PF were $\rho=2.7, F_{1}=0.05, \tau_{\mathrm{F}}=$ $100 \mathrm{msec}, \tau_{\mathrm{D}}=50 \mathrm{msec}, k_{\max }=30 \mathrm{sec}^{-1}, k_{\mathrm{o}}=2 \mathrm{sec}^{-1}, K_{\mathrm{D}}=2$. Model parameters for SC were $\rho=3.2, F_{1}=0.1, \tau_{\mathrm{F}}=100 \mathrm{msec}, \tau_{\mathrm{D}}=50 \mathrm{msec}$, $k_{\text {max }}=18 \mathrm{sec}^{-1}, k_{\mathrm{o}}=2 \mathrm{sec}^{-1}, K_{\mathrm{D}}=1.8$. Parallel fiber data adapted from Kreitzer and Regehr (2000).

significant peak-to-peak variation in EPSC magnitude arose from the interplay between facilitation and depression. As facilitation increased the fraction of activated sites, there were fewer available sites for the next stimulus. During periods of low-frequency activation, CDR boosted synaptic strength by increasing the number of available sites. Thus, the variation in synaptic strength directly reflects the temporal intervals of preceding stimuli according to the FD model. We noted some systematic deviations between the FD model and the data at all three synapses (for example, see the second to last EPSC in the burst of stimuli in Fig. 7). A few possible explanations for the limitations of the FD model are discussed below.

\section{Simulated postsynaptic responses to the FD model}

How does short-term synaptic plasticity contribute to a neuron's ability to influence the firing of its targets? We examined this question using the FD model for presynaptic transmitter release and a single-compartment integrate-and-fire model for spike initiation in the postsynaptic neuron (Fig. 8). The initial EPSP amplitude was adjusted to a range in which individual synapses could fire the postsynaptic cell. This is a greatly simplified situation in that single synaptic inputs do not usually have such a large impact on the postsynaptic neuron, although this situation is akin to "all-or-none" synapses such as brainstem auditory synapses (von Gersdorff et al., 1997), cerebellar climbing fiber synapses (Eccles et al., 1966), and the neuromuscular junction (Betz, 1970). Furthermore, the model for spike initiation did not take into account many features of action potential threshold found in realistic neurons (Llinas, 1988; McCormick, 1990). Despite its obvious limitations, this approach allowed us to explore the manner in which facilitation and CDR might contribute to neuronal firing.

We examined the contribution of CDR and facilitation for two types of presynaptic terminals during a burst stimulus pattern (Fig. 8) in which the synapse was stimulated at 3, 100, and then 3 Hz. For synapse A, the postsynaptic conductance change was chosen to be large enough to fire the postsynaptic neuron with a single presynaptic action potential (Fig. $8 A_{1}, A_{2}$ ). Facilitation was not included in synapse A. In the absence of CDR, the postsynaptic cell was unable to follow the frequency jump from 3 to 100 Hz. After the burst, the postsynaptic cell was unresponsive to low-frequency stimulation until significant recovery from presynaptic depression had occurred (Fig. $8 A_{1}$ ). In contrast, when CDR was included in an otherwise identical synapse, the postsynaptic neuron followed bursts reliably while maintaining low-frequency responsiveness immediately after the burst (Fig. $8 A_{2}$ ). This increased synaptic fidelity was attributable to the boosting of EPSP amplitudes during and after the burst by CDR (Fig. $8 A_{3}$ ).

Synapse B included facilitation, and synaptic strength was adjusted so that at $3 \mathrm{~Hz}$, a single EPSP was well below threshold. In the absence of CDR, synaptic strength transiently increased to suprathreshold levels, and the postsynaptic cell fired once at the onset of high-frequency stimulation. Refractory depression rapidly overcame facilitation and subsequent EPSPs were greatly diminished (Fig. $8 B_{3}$ ). Thus, this type of synapse served as a burst detector: the postsynaptic target fired only when there was a large increase in presynaptic activity. The inclusion of CDR in this synapse resulted in two new postsynaptic behaviors (Fig. $8 B_{2}$ ). First, the postsynaptic neuron fired through the burst, although the rate of firing slowed. Second, the neuron fired again at the onset of lower frequency activity that had previously been subthreshold (Fig. $8 B_{2}$ ). Thus, the synaptic connection demonstrated in Figure $8 B_{2}$ responded to changes in input with increased efficacy for both increases and decreases in stimulation rate. This response requires that the synapse contain both facilitation and CDR, and that recovery from depression occurs more rapidly than does the decay of facilitation.

Although these simulations are based on a number of simplifications, they illustrate some of ways in which facilitation and CDR can influence postsynaptic firing. The postsynaptic behaviors demonstrated in Figure 8 hold true with multiple simulated presynaptic inputs undergoing relatively synchronous changes in firing frequency (data not shown). It will be interesting to examine the interplay between presynaptic properties and more realistic treatments of spike initiation in the postsynaptic cell.

\section{DISCUSSION}

In this study, we developed a model to account for the usedependent changes in transmitter release that were observed during trains at three central synapses. We obtained an analytical expression for synaptic dynamics, which greatly simplify computations of synaptic strength. Although highly reduced, the model captured many of the essential features of use-dependent synaptic dynamics while providing insight into the means by which synapses filter temporal information.

\section{Interpreting $\mathbf{F}$ and $\mathbf{D}$ in terms of presynaptic function}

Despite large differences in behavior at the three synapses reported here, a single scheme provided reasonable descriptions for the underlying plasticities acting at each synapse. Central to our model is the concept that release is proportional to the product of two factors, $F$ and $D$. A calcium-driven reaction enhances release 


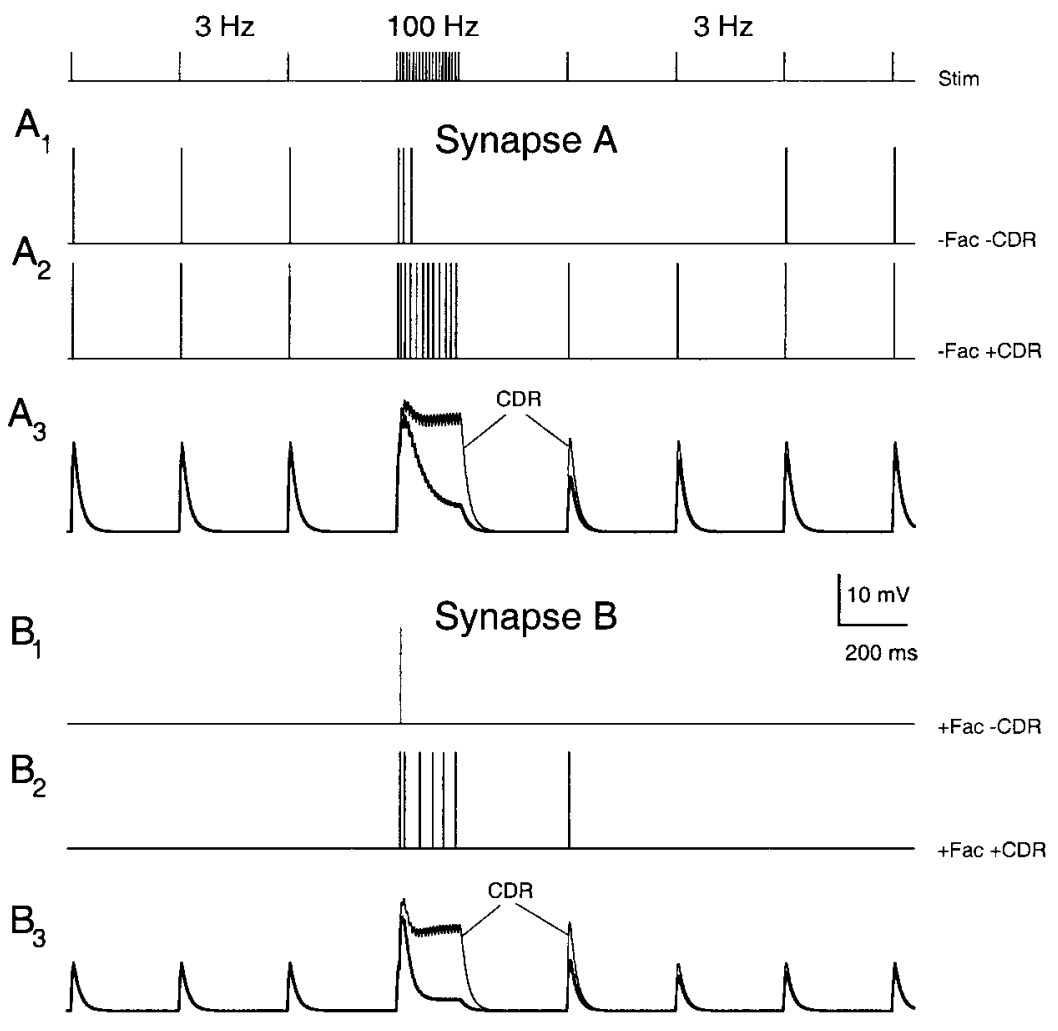

Figure 8. Potential postsynaptic effects of facilitation and CDR. $A_{1}, A_{2}$, Postsynaptic responses of a model integrateand-fire neuron using a single nonfacilitating presynaptic input stimulated at $3 \mathrm{~Hz}$ with a $100 \mathrm{~Hz}$ burst. CDR is absent in $A_{1}(-\mathrm{Fac},-\mathrm{CDR})$ and present in $A_{2}(-\mathrm{Fac},+\mathrm{CDR})$. Synapse A had an initial peak conductance of $15 \mathrm{nS}$ (suprathreshold). $A_{3}$, Postsynaptic potentials for synapse $\mathrm{A}$ with (thin lines) and without CDR (thick lines). $B_{1}, B_{2}$, Postsynaptic responses given the same presynaptic stimulus but facilitation was included. Synapse B had an initial conductance of $6 \mathrm{nS}$ (subthreshold). CDR was absent in $B_{1}$ (+Fac, $-\mathrm{CDR})$ and present in $B_{2}$ (+Fac, +CDR). $B_{3}$, Postsynaptic potentials for synapse $\mathrm{B}$ with (thin lines) and without CDR (thick lines). Model parameters for synapse A were $F_{1}=0.24, \tau_{\mathrm{D}}=50 \mathrm{msec}, k_{\max }=30 \mathrm{sec}^{-1}, k_{\mathrm{o}}=2$ $\mathrm{sec}^{-1}, K_{\mathrm{D}}=2$. Model parameters for synapse B were $\rho=$ $2.5, F_{1}=0.24, \tau_{\mathrm{F}}=100 \mathrm{msec}, \tau_{\mathrm{D}}=50 \mathrm{msec}, k_{\max }=30$ $\mathrm{sec}^{-1}, k_{\mathrm{o}}=2 \mathrm{sec}^{-1}, K_{\mathrm{D}}=2$. Postsynaptic integrate-and-fire neuron parameters: $V_{\text {rest }}=-70 \mathrm{mV}, V_{\text {thresh }}=-55 \mathrm{mV}$, $\tau_{\mathrm{m}}=20 \mathrm{msec}, R_{\mathrm{N}}=100 \mathrm{M} \Omega$.

(increases $F$ ), and entry of release sites into refractory states depresses release (decreases $D$ ). Residual calcium influences both the magnitude of enhancement and the extent of depression. $F$ and $D$ are also coupled by the fact that as $F$ increases, more sites enter refractory states and thus $D$ decreases. The synaptic behavior reported here can be understood in terms of differences in initial probabilities of release as well as the relative contributions of $F$ and $D$. At the climbing fiber synapse, the initial probability of release was high $(\sim 0.35)$, and all of the changes in synaptic strength were attributed to decreases in $D . F$ was kept constant, because there is little if any facilitation at this synapse over a wide range of conditions (Dittman and Regehr, 1998). In models of parallel fiber and Schaffer collateral synapses, however, usedependent changes in both $F$ and $D$ needed to be considered. According to our model, the pronounced differences in the behavior of parallel fiber and Schaffer collateral synapses during repetitive stimulation, which were estimated to be $\sim 0.05$ and 0.25 , respectively, are primarily a reflection of the initial release probability and subsequent changes arising from the coupling between facilitation and depression.

\section{Comparisons with other models}

The approach we take here to model short-term plasticity draws on many studies developed over the past 30 years (Elmqvist and Quastel, 1965; Gingrich and Byrne, 1985; Magleby, 1987; O'Donovan and Rinzel, 1997; Varela et al., 1997). Previous modeling efforts have focused on individual processes such as facilitation (Yamada and Zucker, 1992; Winslow et al., 1994; Bertram et al., 1996) and depression (Takeuchi, 1958; Elmqvist and Quastel, 1965; Betz, 1970; Wu and Borst, 1999), although some have considered the manner in which multiple processes combine to control release (Magleby, 1987; Markram et al., 1998). Some models attempt to be closely tied to an underlying mechanism responsible for synaptic plasticity, whereas others stress mathematical simplicity and general applicability to arbitrary data sets, without explicit reference to particular mechanisms (Abbott et al., 1997).

In this study, we incorporated specific properties of the underlying mechanisms that contribute to synaptic plasticity, while striving to retain computational simplicity. The approach chosen here is based in large part on a $\mathrm{Ca}_{\text {res }}$ model originally put forward by Magleby (1987) for enhancement and depression at the frog neuromuscular junction. The coupling between depression and facilitation here is similar to a recent model of synaptic efficacy, although that study did not distinguish between presynaptic and postsynaptic mechanisms (Markram et al., 1998). However, many aspects of our proposed scheme for plasticity differ from previous descriptions and are based on three recent experimental findings. First, $\mathrm{Ca}_{\text {res }}$ measurements from parallel fibers provided us with information about presynaptic calcium regulation during trains (Regehr and Atluri, 1995). Second, studies of the parallel fibers indicate that facilitation is a slow process driven by $\mathrm{Ca}_{\text {res }}$ (Atluri and Regehr, 1996). Third, the treatment of refractory depression and CDR is derived from our study of the climbing fiber synapse (Dittman and Regehr, 1998). The role of calcium in accelerating recovery from depression has only recently been demonstrated and has rarely been incorporated into models of synaptic plasticity (Gingrich and Byrne, 1985). According to our model, CDR is crucial for maintaining release at synapses during sustained periods of activity, regardless of the initial release probability (Fig. 6).

\section{Limitations of the model}

We made a number of assumptions to achieve computational simplicity (see Results). It is worth elaborating on some of these underlying approximations and limitations of the model so that 
we can understand how to better describe synaptic transmission for an extended range of stimulus conditions.

The present treatment of $\mathrm{Ca}_{\text {res }}$ is highly idealized in that the decay of $\mathrm{Ca}_{\text {res }}$ is assumed to occur with a single exponential component. However, slower components of $\mathrm{Ca}_{\text {res }}$ decay have been observed, particularly after high-frequency stimulation (Regehr, 1997). Inclusion of a slowly decaying component of $\mathrm{Ca}_{\mathrm{res}}$ in the FD model may account for the facilitation observed in the 1-5 $\mathrm{Hz}$ frequency range at both parallel fiber and Schaffer collateral synapses (Fig. $5 B_{2}, C_{2}$ ). Moreover, resting calcium is not considered in this model, although it may contribute to initial release probability and recovery from depression.

Calcium-dependent forms of plasticity are also modeled in an overly simplified manner. The model assumes that facilitation and recovery from depression are driven by chemical reactions with unsaturable sites that respond instantly to changes in $\mathrm{Ca}_{\text {res }}$. As we learn more about calcium cooperativity and kinetics of facilitation and recovery from depression, the accuracy of our model will undoubtedly improve, although at the expense of its simplicity. Additional calcium-dependent mechanisms such as post-tetanic potentiation and delayed release of neurotransmitter may also need to be considered, particularly if we want to model the behavior of synapses for higher-frequency $(>50 \mathrm{~Hz})$ or longerduration $(>5 \mathrm{sec})$ stimulus trains.

Synaptic depression is restricted to a single mechanism in this study. However, other forms of depression related to changes in the size of the readily releasable pool or the buildup of inhibitory factors may play an important role at these and other synapses (Dobrunz et al., 1997; Stevens and Wesseling, 1998). During prolonged periods of presynaptic activity, additional forms of depression that are independent of residual calcium may be needed (Dittman and Regehr, 1998; Galarreta and Hestrin, 1998; Silver et al., 1998). For example, depletion of the readily releasable transmitter pool may dominate synaptic depression after large numbers of stimuli (Stevens and Wesseling, 1998; Schneggenburger et al., 1999), after sustained depolarization of the presynaptic terminal (Wu and Borst, 1999), or during osmotic shock (Rosenmund and Stevens, 1996). This type of depression would likely act in parallel with the refractory-site model proposed here, although further experiments are needed to determine the relationship between these two models of depression. Finally, decreased postsynaptic transmitter sensitivity caused by receptor desensitization was also not incorporated into our model but will need to be considered in a general treatment of shortterm synaptic plasticity (Trussell et al., 1993).

In this study, we consider only the average plasticity of synapses with similar behavior, suppressing both the stochastic nature of release and variability in the initial release probability. Our model may not adequately characterize the postsynaptic response in situations where random fluctuations in release predominate over spike-to-spike changes in release probability. Furthermore, nonuniformities in release probability may be important when activating a small number of release sites with widely disparate release probabilities (Dobrunz and Stevens, 1997). More comprehensive modeling efforts will be needed to evaluate the significance of these properties.

Despite these simplifications, the model describes the behavior of three very different types of synapses remarkably well for various stimulus conditions. It is likely that refining the model as described above would improve its performance at lower frequencies and expand its dynamic range.

\section{Implications for information transfer}

In studying the influence of synaptic activity on the firing pattern of a neuron, it is necessary to consider how the plasticity of neurotransmitter release interacts with the properties of the postsynaptic cell. Using a greatly simplified model of postsynaptic spike initiation, we gained insight into some of the ways in which the facilitation and CDR shape the firing pattern of a synaptically driven cell (Fig. 8). Through these highly reduced simulations, multiple patterns of spiking that are usually ascribed to postsynaptic nonlinearities arose naturally from the use-dependence of transmitter release. Behaviors such as accommodation and rebound excitation could be observed depending on the presence or absence of facilitation and CDR. Temporal filtering features such as burst detection could be demonstrated explicitly (Fig. 8C). It will be interesting to elaborate on the interplay between presynaptic and postsynaptic dynamics using more realistic postsynaptic neurons.

The temporal patterning of spikes has been suggested to carry information from one neuron to the next at numerous vertebrate and invertebrate circuits (Softky and Koch, 1993; Rieke et al., 1997; Usrey and Reid, 1998). During irregular trains, synaptic strength can vary from pulse to pulse and yet maintain high reproducibility for a given stimulus pattern (Zador and Dobrunz, 1997; Dobrunz and Stevens, 1999). In this manner, short-term plasticity allows for the timing of presynaptic spikes to be reflected in the amplitude of the postsynaptic voltage changes (Fig. 1) (Segundo et al., 1963). Thus, the properties of presynaptic terminals may play a critical role in transmitting temporal information to their postsynaptic targets.

\section{REFERENCES}

Abbott LF, Sen K, Varela JA, Nelson SB (1997) Synaptic depression and cortical gain control. Science 275:220-222.

Atluri PP, Regehr WG (1996) Determinants of the time course of facilitation at the granule cell to Purkinje cell synapse. J Neurosci 16:5661-5671.

Bertram R, Sherman A, Stanley EF (1996) Single-domain/bound calcium hypothesis of transmitter release and facilitation. J Neurophysiol 75:1919-1931.

Betz WJ (1970) Depression of transmitter release at the neuromuscular junction of the frog. J Physiol (Lond) 206:629-644.

Delaney KR, Tank DW (1994) A quantitative measurement of the dependence of short-term synaptic enhancement on presynaptic residual calcium. J Neurosci 14:5885-5902.

Delaney KR, Zucker RS, Tank DW (1989) Calcium in motor nerve terminals associated with post-tetanic potentiation. J Neurosci 9:3558-3567.

Del Castillo J, Katz B (1954a) Quantal components of the end-plate potential. J Physiol (Lond) 124:560-573.

Del Castillo J, Katz B (1954b) Statistical factors involved in neuromuscular facilitation and depression. J Physiol (Lond) 124:574-585.

Dittman JS, Regehr WG (1998) Calcium dependence and recovery kinetics of presynaptic depression at the climbing fiber to Purkinje cell synapse. J Neurosci 18:6147-6162.

Dobrunz LE, Stevens CF (1997) Heterogeneity of release probability, facilitation, and depletion at central synapses. Neuron 18:995-1008.

Dobrunz LE, Stevens CF (1999) Response of hippocampal synapses to natural stimulus patterns. Neuron 22:157-166.

Dobrunz LE, Huang EP, Stevens CF (1997) Very short-term plasticity in hippocampal synapses. Proc Natl Acad Sci USA 94:14843-14847.

Eccles JC, Katz B, Kuffler SW (1941) Nature of the "endplate potential" in curarized muscle. J Physiol (Lond) 124:574-585.

Eccles J, Llinas R, Sasaki K (1964) Excitation of cerebellar Purkinje cells by the climbing fibers. Nature 203:245-246.

Eccles JC, Llinas R, Sasaki K (1966) The excitatory synaptic action of climbing fibers on the Purkinje cells of the cerebellum. J Physiol (Lond) 182:268-296.

Elmqvist D, Quastel DMJ (1965) A quantitative study of end-plate potentials in isolated human muscle. J Physiol (Lond) 178:505-529. 
Feller MB, Delaney KR, Tank DW (1996) Presynaptic calcium dynamics at the frog retinotectal synapse. J Neurophysiol 76:381-400.

Feng TP (1941) Studies on the neuromuscular junction. Clin J Physiol 16:341-372.

Galarreta M, Hestrin S (1998) Frequency-dependent synaptic depression and the balance of excitation and inhibition in the neocortex. Nat Neurosci 1:587-594.

Gingrich KJ, Byrne JH (1985) Simulation of synaptic depression, posttetanic potentiation, and presynaptic facilitation of synaptic potentials from sensory neurons mediating gill-withdrawal reflex in Aplysia. J Neurophysiol 53:652-669.

Helmchen F, Borst JGG, Sakmann B (1997) Calcium dynamics associated with a single action potential in a CNS presynaptic terminal. Biophys J 72:1458-1471.

Herrington J, Bookman RJ (1995) Pulse control v4.5: IGOR XOPS for patch-clamp data aquisition. Miami, FL: University of Miami.

Kamiya H, Zucker RS (1994) Residual $\mathrm{Ca}^{2+}$ and short-term synaptic plasticity. Nature 371:603-606.

Katz B, Miledi R (1968) The role of calcium in neuromuscular facilitation. J Physiol (Lond) 195:481-492.

Kreitzer AC, Regehr WG (2000) Modulation of transmission during trains at a cerebellar synapse. J Neurosci 20:000-000.

Lisman JE (1997) Bursts as a unit of neural information: making unreliable synapses reliable. Trends Neurosci 20:38-43.

Llano I, Marty A, Armstrong CM, Konnerth A (1991) Synaptic- and agonist-induced excitatory currents of Purkinje cells in rat cerebellar slices. J Physiol (Lond) 434:183-213.

Llinas RR (1988) The intrinsic electrophysiological properties of mammalian neurons: insights into central nervous system function. Science 242:1654-1664.

Magee J, Hoffman D, Colbert C, Johnston D (1998) Electrical and calcium signaling in dendrites of hippocampal pyramidal neurons. Annu Rev Physiol 60:327-346.

Magleby KL (1987) Short-term changes in synaptic efficacy. In: Synaptic function (Edelman GM, Gall WE, Cowan WM, eds), pp. 21-56. New York: Wiley.

Markram H, Pikus D, Anirudh G, Tsodyks M (1998) Potential for multiple mechanisms, phenomena, and algorithms for synaptic plasticity at single synapses. Neuropharmacology 37:489-500.

McCormick DA (1990) Membrane properties and neurotransmitter actions. In: The synaptic organization of the brain (Shepherd GM, ed), pp. 32-66. New York: Oxford UP.

Mintz IM, Sabatini BL, Regehr WG (1995) Calcium control of transmitter release at a cerebellar synapse. Neuron 15:675-688.

O’Donovan MJ, Rinzel J (1997) Synaptic depression: a dynamic regulator of synaptic communication with varied functional roles. Trends Neurosci 20:431-433.

Regehr WG (1997) Interplay between sodium and calcium dynamics in granule cell presynaptic terminals. Biophys J 72:2476-2488.

Regehr WG, Atluri PP (1995) Calcium transients in cerebellar granule cell presynaptic terminals. Biophys J 68:2156-2170.

Rieke F, Warland D, de Ruyter van Steveninck R, Bialek W (1997) Spikes: exploring the neural code. Cambridge, MA: MIT.

Rosenmund C, Stevens CF (1996) Definition of the readily releasable pool of vesicles at hippocampal synapses. Neuron 16:1197-1207.

Schneggenburger R, Meyer AC, Neher E (1999) Released fraction and total size of a pool of immediately available transmitter quanta at a calyx synapse. Neuron 23:399-409.

Segundo JP, Moore GP, Stensaas LJ, Bullock TH (1963) Sensitivity of neurones in Aplysia to the temporal pattern of arriving impulses. J Exp Biol 40:643-667.

Selig DK, Nicoll RA, Malenka RC (1999) Hippocampal long-term potentiation preserves the fidelity of postsynaptic responses to presynaptic bursts. J Neurosci 19:1236-1246.
Silver RA, Momiyama A, Cull-Candy SG (1998) Locus of frequencydependent depression identified with multiple-probability fluctuation analysis in rat climbing fibre-Purkinje cell synapses. J Physiol (Lond) 510:881-902.

Sinha SR, Wu LG, Saggau P (1997) Presynaptic calcium dynamics and transmitter release evoked by single action potentials at mammalian central synapses. Biophys J 72:637-651.

Softky WR, Koch C (1993) The highly irregular firing of cortical cells is inconsistent with temporal integration of random EPSPs. J Neurosci 13:334-350.

Stevens CF, Wang Y (1995) Facilitation and depression at single central synapses. Neuron 14:795-802.

Stevens CF, Wesseling JF (1998) Activity-dependent modulation of the rate at which synaptic vesicles become available to undergo exocytosis. Neuron 21:415-424.

Swandulla D, Hans M, Zipser K, Augustine GJ (1991) Role of residual calcium in synaptic depression and posttetanic potentiation: fast and slow calcium signaling in nerve terminals. Neuron 7:915-926.

Takeuchi A (1958) The long-lasting depression in neuromuscular transmission of frog. Jpn J Physiol 8:102-113.

Trussell LO, Fischbach GD (1989) Glutamate receptor desensitization and its role in synaptic transmission. Neuron 3:209-218.

Trussell LO, Zhang S, Raman IM (1993) Desensitization of AMPA receptors upon multiquantal neurotransmitter release. Neuron 10:1185-1196.

Usrey WM, Reid RC (1998) Synchronous activity in the visual system. Annu Rev Physiol 61:435-456.

Varela JA, Sen K, Gibson J, Fost J, Abbott LF, Nelson SB (1997) A quantitative description of short-term plasticity at excitatory synapses in layer $2 / 3$ of rat primary visual cortex. J Neurosci 17:7926-7940.

von Gersdorff H, Schneggenburger R, Weis S, Neher E (1997) Presynaptic depression at a calyx synapse: the small contribution of metabotropic glutamate receptors. J Neurosci 17:8137-8146.

Wang LY, Kaczmarek LK (1998) High-frequency firing helps replenish the readily releasable pool of synaptic vesicles. Nature 394:384-388.

Winslow JL, Duffy SN, Charlton MP (1994) Homosynaptic facilitation of transmitter release in crayfish is not affected by mobile calcium chelators: implications for the residual ionized calcium hypothesis from electrophysiological and computational analyses. J Neurophysiol 72:1769-1793.

Wu LG, Borst JGG (1999) The reduced release probability of releasable vesicles during recovery from short-term synaptic depression. Neuron 23:821-832.

Yamada WM, Zucker RS (1992) Time course of transmitter release calculated from simulations of a calcium diffusion model. Biophys $\mathbf{J}$ 61:671-682.

Zador A, Dobrunz L (1997) Dynamic synapses in the cortex. Neuron 19:1-4.

Zengel JE, Magleby KL, Horn JP, McAfee DA, Yarowsky PJ (1980) Facilitation, augmentation, and potentiation of synaptic transmission at the superior cervical ganglion of the rabbit. J Gen Physiol 76:213-231.

Zhao M, Hollingworth S, Baylor SM (1996) Properties of tri- and tetracarboxylate $\mathrm{Ca}^{2+}$ indicators in frog skeletal muscle fibers. Biophys $\mathrm{J}$ 70:896-916.

Zucker RS (1989) Short-term synaptic plasticity. Annu Rev Neurosci 12:13-31.

Zucker RS (1999) Calcium- and activity-dependent synaptic plasticity. Curr Opin Neurobiol 9:305-313.

Zucker RS, Stockbridge N (1983) Presynaptic calcium diff usion and the time courses of transmitter release and synaptic facilitation at the squid giant synapse. J Neurosci 3:1263-1269. 